\title{
Residual Ultimate Strength of Cracked Steel Unstiffened and Stiffened Plates under Longitudinal Compression
}

\author{
Abbas Bayatfar ${ }^{a, *}$, Mohammad Reza Khedmati ${ }^{\mathrm{b}}$, Philippe Rigo \\ ${ }^{a}$ Research Associate, ANAST, University of Liege, Chemin des Chevreuils 1 (B52/3), 4000 Liège, Belgium \\ ${ }^{\mathrm{b}}$ Associate Professor, Faculty of Marine Technology, Amirkabir University of Technology, Tehran 15914, Iran \\ ${ }^{\mathrm{c}}$ Professor, ANAST, University of Liege, Chemin des Chevreuils 1 (B52/3), 4000 Liège, Belgium
}

* Corresponding author: Tel.: (32-4)3669341, Fax: (32-4)3669133.

E-mail address: a.bayatfar@ulg.ac.be (Abbas Bayatfar.) 


\begin{abstract}
This paper numerically deals with the influence of cracks (in terms of length and location) on the ultimate compressive strength characteristics of unstiffened and stiffened plate elements used in thin-walled structures. The cracks were presumed to be through-thickness, having no contact between their faces and no propagation was allowed. A series of nonlinear finite element analyses was conducted using ANSYS commercial finite element code in which the Newton-Raphson method has been employed to solve the nonlinear governing equations.

This study indicates that the length of cracks and especially its location can significantly affect the ultimate strength characteristics of unstiffened and stiffened plate elements subjected to axial compressive action.
\end{abstract}

Keywords: Ultimate strength; Cracked steel plate; Initial deflection; Longitudinal compression; Nonlinear Finite Element Analysis 
Notation

$b$

E

$h_{w}$

$m$

$t_{p}$

$t_{w}$

$w_{0}$

$w_{0 c}$

$w_{0 p l}$

$w_{0 s}$

$r(=\sqrt{I / A})$

$\beta\left(=b \times \sqrt{\sigma_{Y} / E} / t_{p}\right)$

$\lambda\left(=a \times \sqrt{\sigma_{Y} / E} /(\pi r)\right)$

$\varepsilon$

$\varepsilon_{Y}$

$\sigma_{Y}$

$v$
Plate length

Plate breadth

Young's modulus

Web height

Buckling mode half wave number

Plate thickness

Web thickness

Plating initial distortion function

Column-type initial distortion function

Maximum plate initial deflection

Sideways initial distortion function

Gyration radius

Plate slenderness parameter

Column slenderness parameter

Strain

Yield strain $\left(=\sigma_{Y} / E\right)$

Yield stress

Poisson's ratio 


\section{Introduction}

A significant feature of ship structural design is to describe the structural behaviour of ship hull girder and to accurately predict its maximum load-carrying capacity. On the other hand, the overall failure of ship structure (which is basically an assembly of unstiffened and stiffened plate components), is certainly affected and governed by the plastic collapse of its structural elements. Therefore, from the Ultimate Limit State (ULS) design point of view, a primary task is to predict the ultimate strength of such foregoing structural members in order to assess the safety and economical design of ship structures. In this regard, it is required to consider all the parameters and factors which are involved in the fabrication process and service life. Among them, initial distortions and crack defects may be mentioned which have been taken into account in this paper.

The unstiffened and stiffened plate components in a steel thin-walled structure such as a ship are typically fabricated and assembled by flame cutting and fusion welding. Over these processes, the intense local heating and cooling essentially causes initial imperfections in terms of residual stresses and initial distortions in the respective structural components. These initial imperfections affect the load-carrying capacity of unstiffened and stiffened plate elements. Thus they must be considered in ultimate strength assessment as influential parameters. Moreover, thin-walled structures such as ships made of metals are prone to various types of defects and damages when being in operational use (especially in aged conditions). One of the most important defects is cracking that can considerably affect the load-bearing capacity of panels and therefore of entire ships. Cracks may be initiated at any locations (particularly in welded joints and local areas of stress concentrations) over fabrication process or due to fatigue and impact loads. Then they grow under different dynamic loadings and/or monotonic extreme loadings during service life resulting in various sizes and orientations throughout the ship structure. Such cracking damages may reduce the load-carrying capacity of the entire structure. Accordingly, it is of crucial importance to study and understand the ultimate strength characteristics of structural members such as unstiffened and stiffened plates under damaged conditions in damage-tolerant design procedure and during service life.

A large number of studies have been performed in order to investigate the influence of initial imperfections (i.e. residual stresses and initial distortions) on the strength characteristics of steel-plated structural components. Although they are too numerous to list, references may be made to some of the latest ones [1-4]. Also, many efforts have been carried out concerning the cracking damage, mostly dealing with it from fatigue limit state point of view. Wang et al. [5-6] and Xiao-dong et al. [7] studied the problems of crack initiation and propagation 
due to fatigue loading. Nevertheless, the available literature on the strength characteristics of cracked steel unstiffened and stiffened plates under monotonic loading are quite limited [8-15]. Furthermore, the prime concern of them is to make an investigation under monotonic tensile loading or an estimation of elastic buckling strength. The ultimate strength of cracked steel plates under monotonic loading has received some attention in the recent years by some investigators like Paik et al. [16-18] in which some numerical/experimental studies on the collapse behaviour of plates suffering straight cracks under both monotonic tensile and compressive loads have been carried out. Also, the work done by Margaritis et al. [19] through which the ultimate strength and collapse response of stiffened plates having straight cracks has been studied by using a series of nonlinear finite element (FE) analyses. However, due to limited contributions on this topic further studies are required to reach a deeper insight into the strength characteristics of the plated elements suffering cracks.

According to the above literature review and also in compliance with the design requirements of maritime industries, the study on the ultimate strength characteristics of cracked steel unstiffened and stiffened plates has been undertaken. In this regard, this paper presents the results of a numerical study carried out on the ultimate compressive strength characteristics of cracked steel unstiffened and stiffened plate components, used in a thinwalled structure such as ship hull girders, considering the effects of initial deflections. The main objective of the present paper is to investigate the influence of crack location and crack length on the ultimate strength characteristics of those structural elements under monotonic longitudinal axial compression. This investigation is based on the reduced cross-sectional area as an easier alternative to crack considerations from fracture mechanics point of view [16]. In fact, the cracks were presumed to be through-thickness, having no contact between their faces and no propagation was allowed. The cracks modelled herein are assumed to be straight originally and also remain straight during loading, while their length is also considered to be fixed. Of course such an assumption cannot be generalised in real practice, since the cracks may happen either in linear or nonlinear forms. Besides, cracks may be propagated in any direction.

Flat-bar profile is the considered stiffener type in this study and materials are in the category of high strength steel alloys. In order to reach our goal, a series of nonlinear finite element analyses was conducted using ANSYS commercial finite element code in which the Newton-Raphson method has been employed to solve the nonlinear governing equations. 


\section{Finite element modelling}

\subsection{Extent and geometry}

Two structural elements, i.e. unstiffened and stiffened plates, have been considered in the present investigation as one-bay/one-span models. Extent and geometrical dimensions of these models have been, to some extent, taken from the report of Ship Structure Committee [20], Fig. 1. The unstiffened plate element is $2000 \mathrm{~mm}, 500 \mathrm{~mm}$ and $10 \mathrm{~mm}$ in length $(a)$, breadth $(b)$ and thickness $\left(t_{p}\right)$, respectively. The stiffened plate element is consisted of the same plate with flat-bar profile $120 \mathrm{~mm} \times 7 \mathrm{~mm}$, i.e. $120 \mathrm{~mm}$ high $\left(h_{w}\right)$ and $7 \mathrm{~mm}$ $\operatorname{thick}\left(t_{w}\right)$.

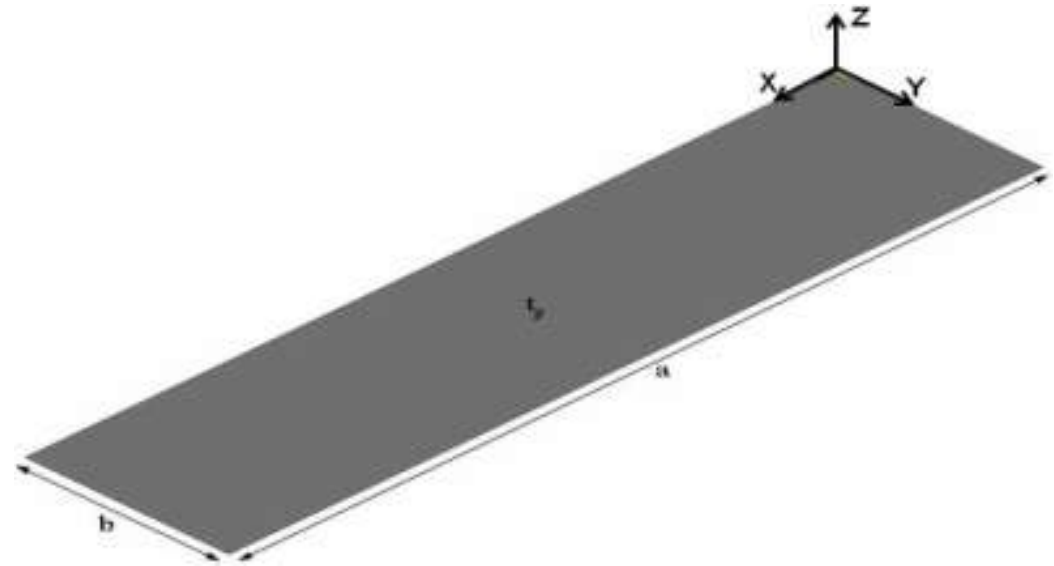

a) Unstiffened plate

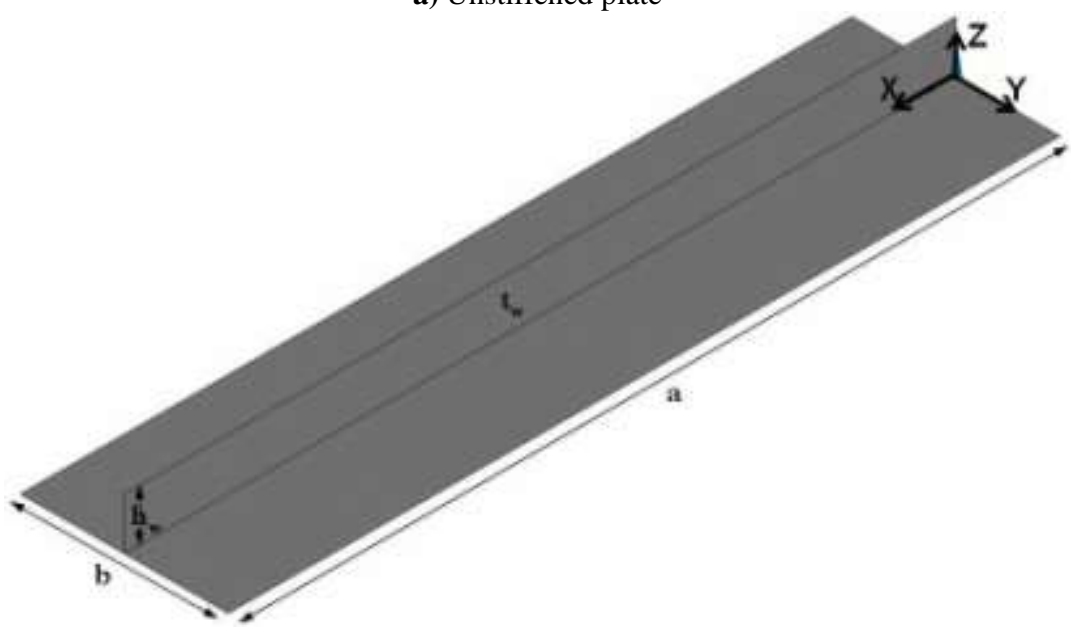

b) Stiffened plate

Fig. 1. Unstiffened and stiffened plate elements

\subsection{Cases studied with respect to crack defect}

In order to consider various locations of crack defect, the following six models have been constructed as shown in Table 1. The first four and the last two models are related to cracked unstiffened and stiffened plate elements, respectively. Furthermore, in order to consider various crack lengths, each of these models is also 
divided into different cases for the analysis purposes. The crack length has been assumed to be a certain proportion of the breadth of the corresponding plate with the ratio ranging from 0.1 to 0.5 . Table 1 describes the analysed cases in more details. Herein, it should be mentioned that the crack has been only taken as throughthickness cracking for safety considerations, while crack propagation is not considered. The size of the gap between the crack faces is taken equal to $3 \mathrm{~mm}$, in order to avoid contact between the crack faces.

Table 1

Models for analysis

\begin{tabular}{|c|c|c|}
\hline Model & Description & Figure \\
\hline U & $\begin{array}{l}\text { The unstiffened plate in which the crack is transversally (Y-axis } \\
\text { direction) located in the centre of the plate; e.g. UTC10\% means } \\
\text { that the crack length is } 10 \% \text { of the plate breadth. }\end{array}$ & \\
\hline 됨 & $\begin{array}{l}\text { The unstiffened plate in which the crack is transversally located } \\
\text { in the middle of one longitudinal edge; e.g. UT1E10\% means } \\
\text { that the crack length is } 10 \% \text { of the plate breadth. }\end{array}$ & \\
\hline 空 & $\begin{array}{l}\text { The unstiffened plate in which two cracks are transversally } \\
\text { located in the middle of both longitudinal edges and their } \\
\text { lengths altered from } 0.1 \text { to } 0.5 \text { of half the plate breadth; e.g. } \\
\text { UT2E } 10 \% \text { means that the crack lengths are } 10 \% \text { of half the plate } \\
\text { breadth. }\end{array}$ & \\
\hline 恿 & $\begin{array}{l}\text { The unstiffened plate in which the crack is transversally located } \\
\text { and moved along one longitudinal edge. The crack length is } \\
\text { constant and taken } 40 \% \text { of the plate breadth (i.e. } 200 \mathrm{~mm} \text { ) which } \\
\text { is moved from loaded transverse (short) edge every } 250 \mathrm{~mm} \text {; e.g. } \\
\text { UT1E-L } 250 \text { means that the location of crack is } 250 \mathrm{~mm} \text { away } \\
\text { from the loaded transverse (short) edge. }\end{array}$ & \\
\hline$\underset{n}{U}$ & $\begin{array}{l}\text { The stiffened plate in which the crack is transversally located in } \\
\text { the centre of the plate; e.g. STC10\% means that the crack length } \\
\text { is } 10 \% \text { of the plate breadth. }\end{array}$ & \\
\hline$\frac{3}{n}$ & $\begin{array}{l}\text { The stiffened plate in which two cracks have been considered. } \\
\text { First one is transversally located in the centre of the plate with } \\
\text { constant length } 20 \% \text { of the plate breadth (i.e. } 100 \mathrm{~mm} \text { ). The } \\
\text { second one which is vertically located in the middle of the } \\
\text { longitudinal edge of web-plate junction; e.g. STCW } 10 \% \text { means } \\
\text { that the web plating crack length is } 10 \% \text { of the web plate height. }\end{array}$ & \\
\hline
\end{tabular}


In addition, there are two analysed cases without any cracks as reference models, which have been taken in order to establish a comparison basis for damaged cases (i.e. to investigate the effect of cracking damage on the ultimate strength characteristics). These models called as 'REF' henceforth.

\subsection{Mechanical properties of material}

The material used in this study is in the category of high strength steel alloys, the properties of which have been taken from [20]. The material was considered to behave in an elastic-plastic-hardening manner with a yield stress of $\sigma_{Y}=425 \mathrm{MPa}$ (Fig. 2). The elastic modulus of material is $E=200.5 \mathrm{GPa}$ and Poissons's ratio is $v=0.3$.

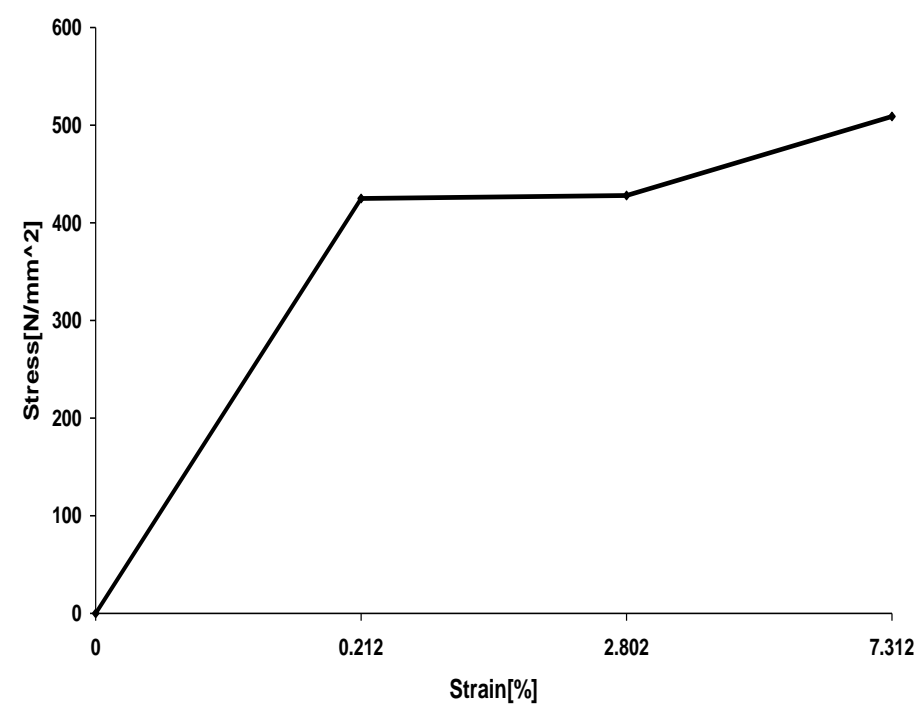

Fig. 2. Average stress-average strain curve of material

\subsection{Finite element code and adopted elements}

The commercial finite element code ANSYS [21] has been used for all analyses. Among the elements included in the ANSYS library, the SHELL181 element has been selected in order to discretise the cracked unstiffened and stiffened plate models. SHELL181 is suitable for analysing thin to moderately-thick shell structures which falls into the domain of plate thicknesses used for ship building. It is a 4-node element with six degrees of freedom at each node: translations in the $X, Y$ and $Z$ directions, and rotations about the $X, Y$ and $Z$-axes. This element is well-suited for linear, large rotation, and/or large strain nonlinear applications [21]. In this regard, Fig. 5 shows typical mesh generations used in nonlinear finite element analysis. 


\subsection{Initial distortions}

Different types of initial imperfections are usually produced in the plated elements, among them only initial distortions have been considered in the present study. The initial distortions have been taken at average levels as are often appeared within the maritime industry. Three types of initial deflections have been considered, namely plating, column-type and sideways initial deflections which are relevant to welded-metal plate structures. The initial distortion shape in unstiffened plate models has been taken as buckling mode defined by the equation $\omega_{0}=\omega_{0 p l} \sin (m \pi x / a) \sin (\pi y / b)$ in which the values of $\mathrm{m}$ and $\omega_{0 p l}$ are respectively equal to $\mathrm{a} / \mathrm{b}$ and $0.1 \beta^{2} t_{p}$ [22]. By substituting these terms, the final equation of plating initial distortion to apply in finite element modelling is as $\omega_{0}=5.3 \sin (\pi x / 500) \sin (\pi y / 500)$. Fig. 3(a) shows a typical plating initial distortion (with magnification of $\mathrm{x} 10$ ) in model 'UTC'.

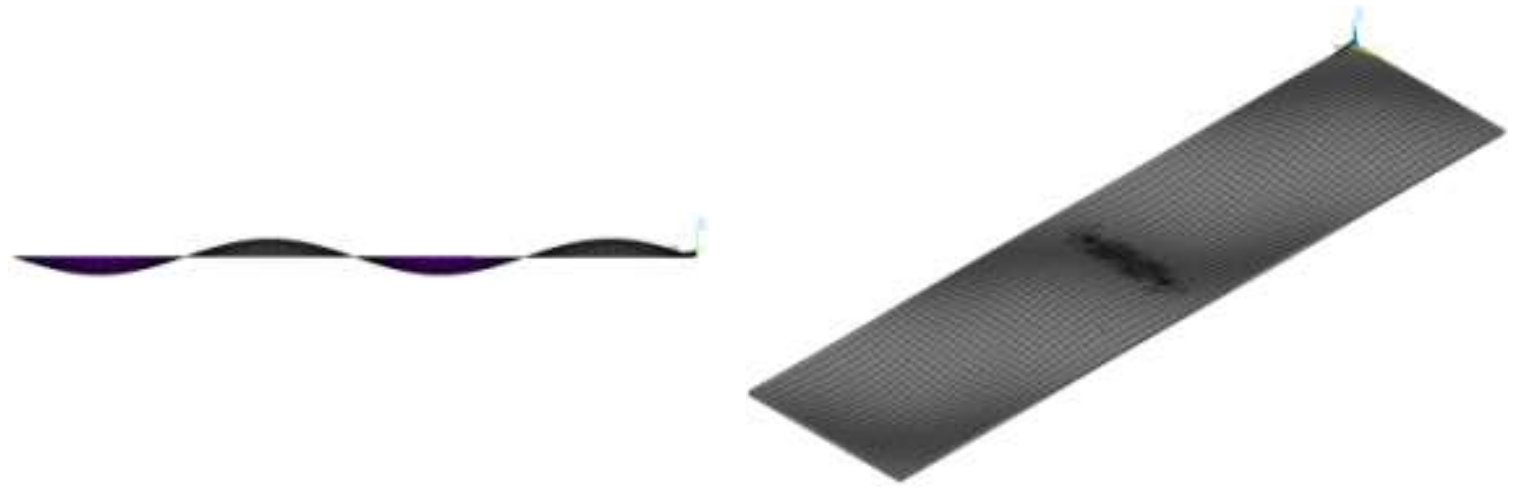

a) Model 'UTC'
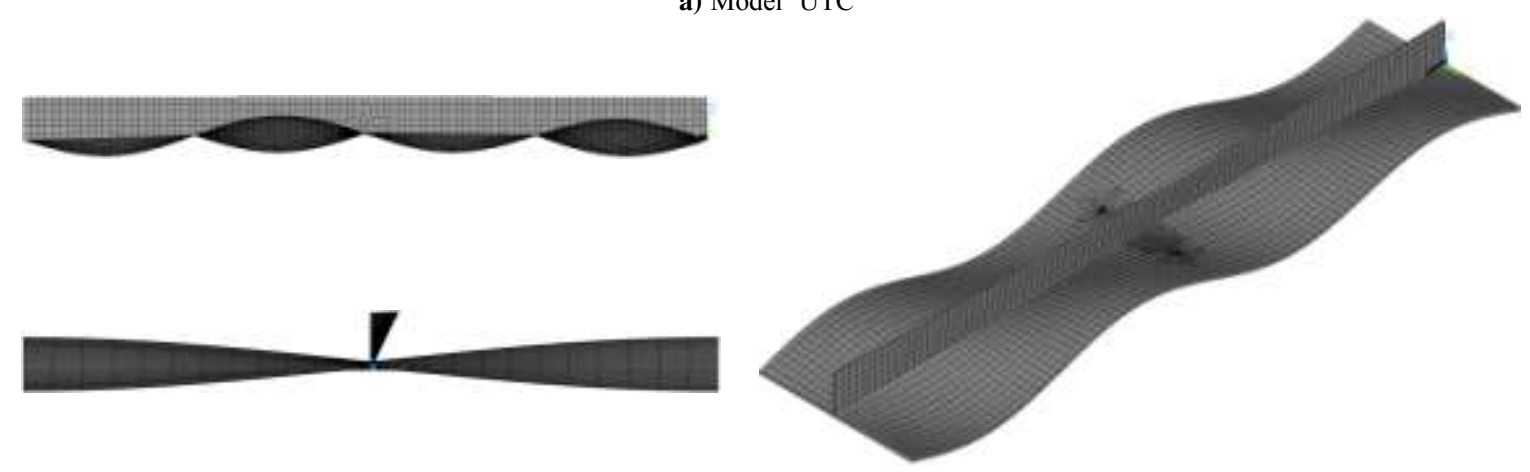

b) Model 'STC'

Fig. 3. Two typical initial distortions for cracked unstiffened and stiffened plates (with magnification of $\times 10$ )

The initial distortion shape of stiffened plate models has been considered as combination of abovementioned plating initial deflection, column-type $\left(\omega_{0 c}=B_{0} \sin (\pi x / a)\right)$ and sideways 
$\left(\omega_{0 s}=C_{0} z \sin (\pi x / a) / h\right.$ ). The values of ${ }^{B_{0}}$ and $C^{C_{0}}$ have been assumed to be $0.001 a$ in accordance with [2324]. Figure 3(b) shows a typical case in model 'STC' in this regard.

\subsection{Boundary \& loading conditions}

Cracked unstiffened or stiffened plate models are assumed to be extracted out of a continuous plated structure such as a deck of a ship hull girder. Thus, proper boundary and loading conditions have to be imposed along the boundaries so that they can simulate real behaviour as accurate as possible. Figure 4 depicts the state of boundary/loading conditions of the two unstiffened/stiffened cracked plate models.

Simply-supported straight boundaries are adopted for longitudinal edges of unstiffened cracked plate models. Uniform compressive displacement is applied on the simply-supported straight loading edge, while its opposite simply-supported edge is restrained against in-plane movement.

In the case of stiffened cracked plate model, longitudinal edges are assumed to have symmetrical conditions. Moreover, uniform compressive displacement is applied on the simply-supported straight loading edge, while its opposite simply-supported edge is restrained against in-plane movement.

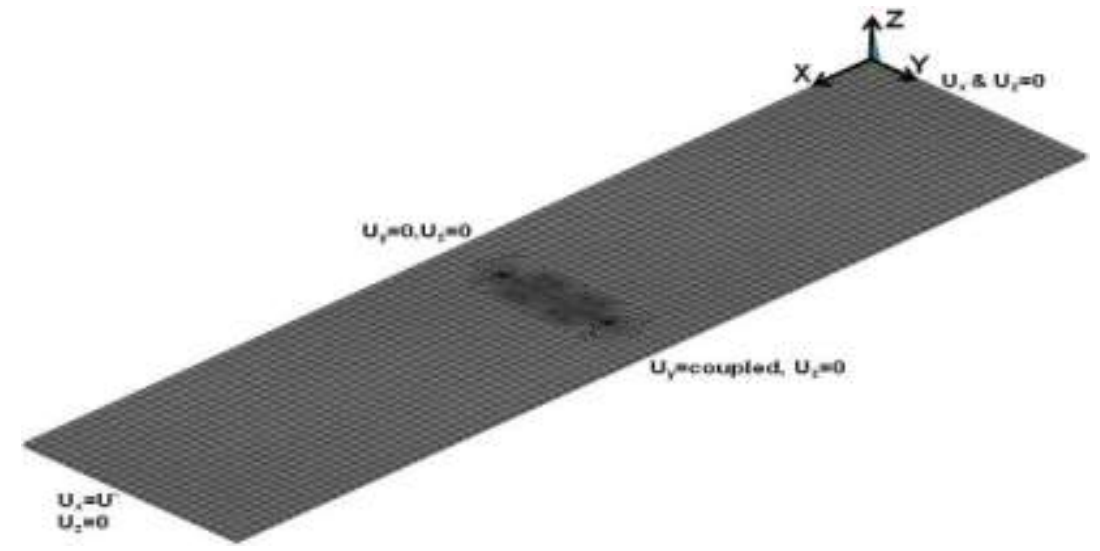

a) Model 'UTC'

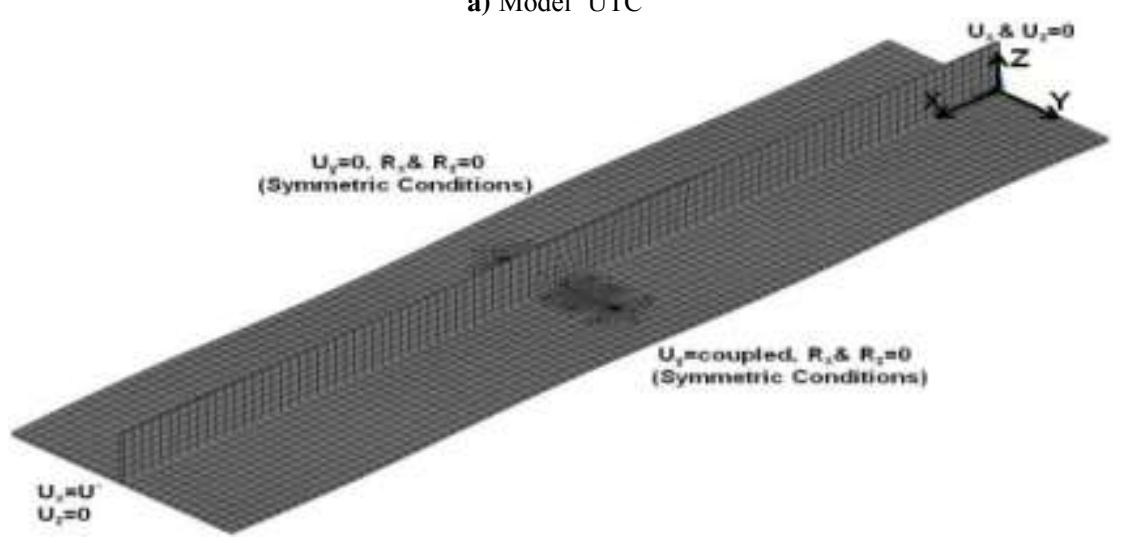

b) Model 'STC'

Fig. 4. Boundary and loading conditions for cracked unstiffened and stiffened plates 


\section{Finite element analysis}

Calculation of the ultimate strength of a structural model is inherently a nonlinear problem that mainly includes both material and geometric nonlinearities from structural mechanics point of view. There are some equation-solving techniques applicable to the nonlinear governing equations which typically are the NewtonRaphson and Arc-length methods. In this regard, reference may be made to Cook et al. [25] and Paik et al. [26]. Commercial FEM code ANSYS [21] is used herein for performing nonlinear finite element analyses. In what follows, different aspects of finite element meshing are presented.

\subsection{Convergence study}

In order to determine the best size of elements based on a compromise between computational cost and accuracy, two types of mesh generations have been considered for both cracked unstiffened and stiffened plates Fig. 5.

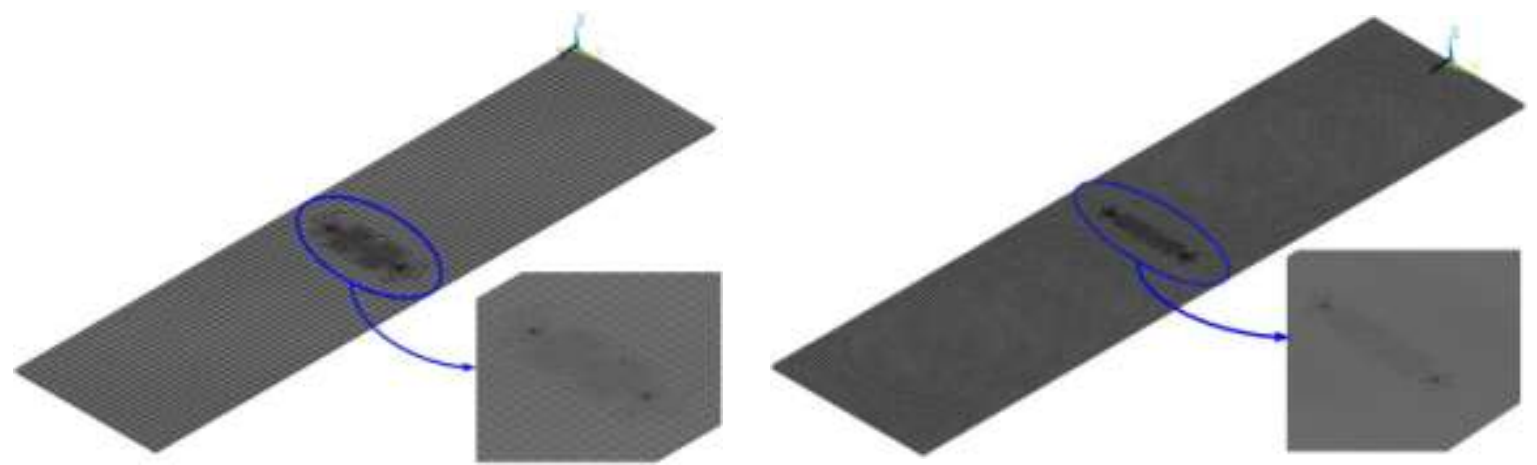

a) UTC50\%
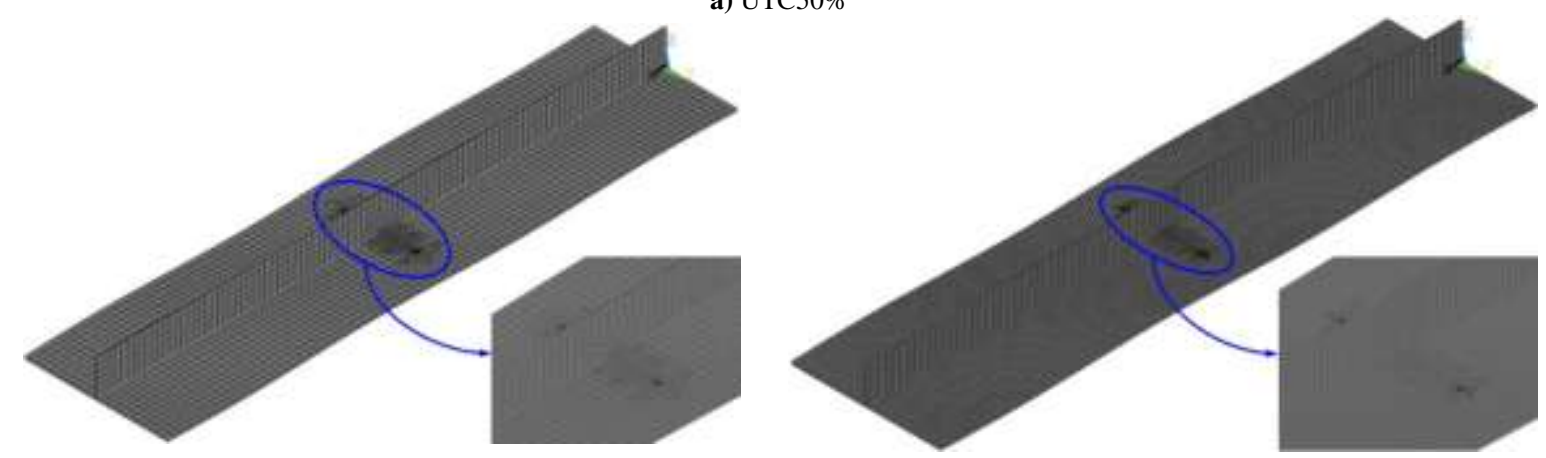

b) $\mathrm{STC} 50 \%$

Fig. 5. Typical mesh generations (left side: Coarse Mesh, right side: Fine Mesh)

Table 2 describes these two types of mesh generations in case of UTC50\% and STC50\% models. As it can be seen, there is no significant difference between the obtained values of ultimate strengths. 
Table 2

Results of mesh density study

\begin{tabular}{|c|c|c|c|c|c|c|c|}
\hline \multicolumn{2}{|c|}{ Case } & $\begin{array}{c}\text { Number of } \\
\text { elements } \\
\text { along longitudinal } \\
\text { edges }\end{array}$ & $\begin{array}{c}\text { Number of } \\
\text { elements } \\
\text { along transverse } \\
\text { edges }\end{array}$ & $\begin{array}{c}\text { Number of } \\
\text { elements } \\
\text { along web } \\
\text { height }\end{array}$ & $\begin{array}{c}\text { Total } \\
\text { number of } \\
\text { elements }\end{array}$ & $\begin{array}{c}\text { Ultimate } \\
\text { strength } \\
(\mathrm{MPa})\end{array}$ & $\begin{array}{l}\text { Difference } \\
\quad \% \\
(\%)\end{array}$ \\
\hline \multirow[t]{2}{*}{ UTC50\% } & $\begin{array}{c}\text { Coarse } \\
\text { Mesh }\end{array}$ & 95 & 24 & - & 2872 & 245.2 & - \\
\hline & Fine Mesh & 200 & 50 & - & 10334 & 252.7 & +3 \\
\hline \multirow{2}{*}{ STC50\% } & $\begin{array}{c}\text { Coarse } \\
\text { Mesh }\end{array}$ & 95 & 24 & 6 & 3415 & 205.5 & - \\
\hline & Fine Mesh & 200 & 50 & 12 & 12875 & 210.5 & +2.4 \\
\hline
\end{tabular}

In this regard, the obtained average stress-average strain relationships along with their deflection modes superimposed on the spreads of yielding at the ultimate strength states are represented in Fig. 6.

\footnotetext{
${ }^{1}$ Compared with the case 'Coarse Mesh'
} 


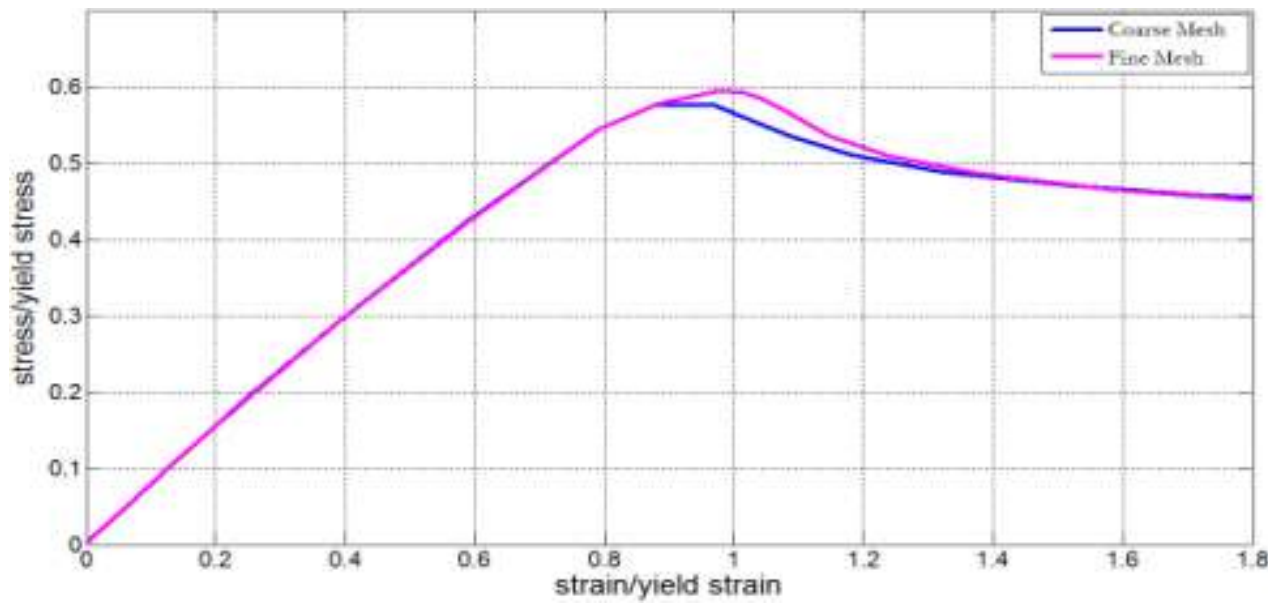

a) Nondimensional average stress-average strain curves

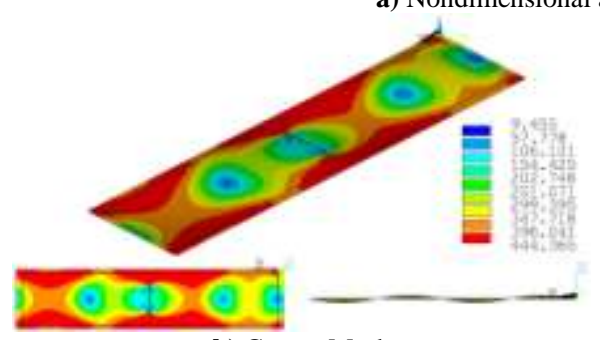

b) Coarse Mesh

Fig. 6-1. UTC50\%

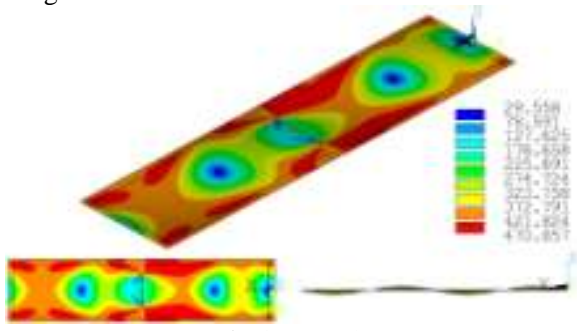

c) Fine Mesh

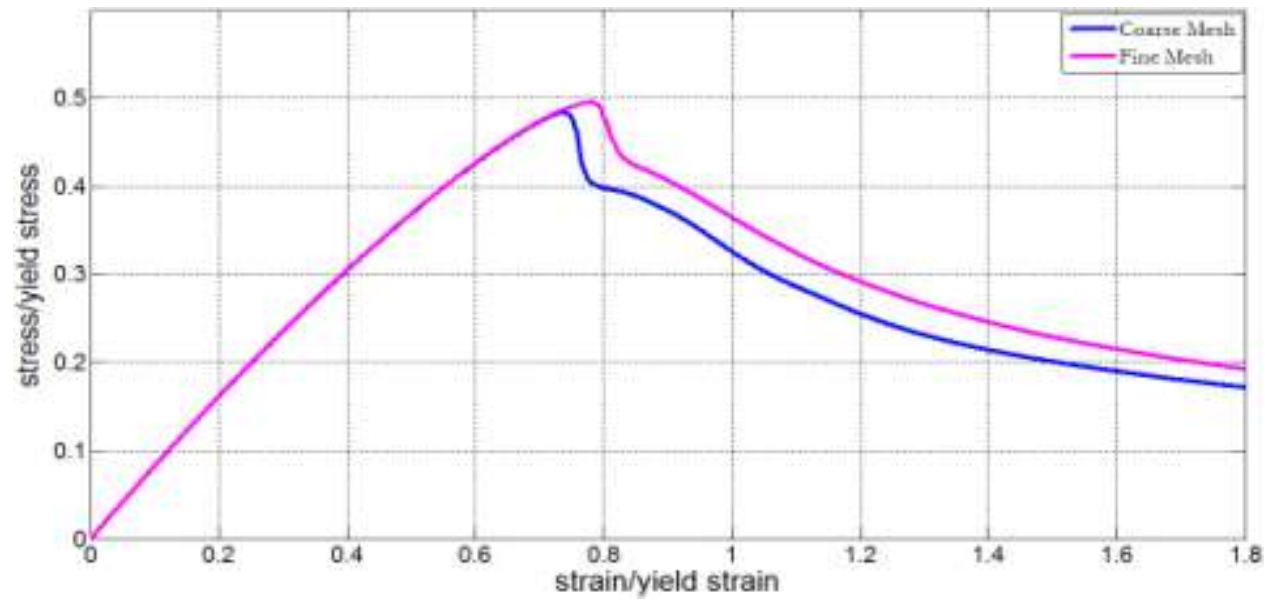

a) Nondimensional average stress-average strain curves

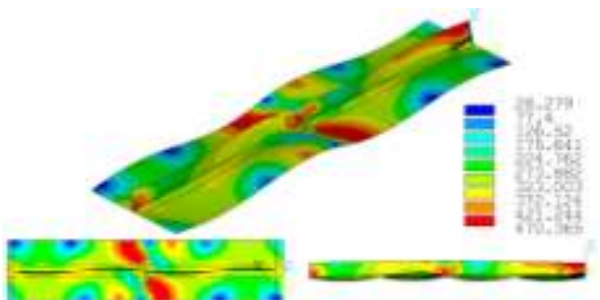

b) Coarse Mesh

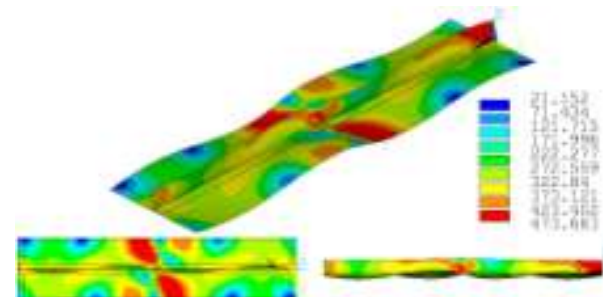

c) Fine Mesh

Fig. 6-2. STC50\%

Fig. 6. Convergence study for the models UTC50\% and STC50\%. (a) nondimensional average stress-average strain curves (b)-(c) deflection modes, and spreads of yielding (in MPa) at ultimate strength level (with magnification of $\times 5$ )

As a result of such a convergence study, the case 'Coarse Mesh' has been chosen and the rest of mesh generations for the other analysed cases are on this basis. 


\subsection{Model verification}

Prior to starting nonlinear finite element analyses, sensitivity of the ultimate strength values for uncracked models with the both Newton-Raphson and Arc-length methods is studied. The results of this sensitivity analysis are reported in Table 3, and are compared with some existing empirical formulations (i.e. Paik's and Faulkner's expressions). In Newton-Raphson method, longitudinal axial compressive loading has been simulated through either displacement control or force control that are respectively called as 'NR-D' and 'NR-F' in Table 3; whilst the imposed displacement control was adopted in the Arc-length method, that is called as 'AL-D' in Table 3. As it can be seen from this table, there is no significant difference in accuracy between the obtained values of the ultimate strengths through selection of these two foregoing methods.

\section{Table 3}

Sensitivity of the ultimate strength values of uncracked unstiffened plate and stiffened plate models to the application of Newton-Raphson (NR) and Arc-Length (AL) procedures

\begin{tabular}{|c|c|c|c|c|c|c|}
\hline \multirow{2}{*}{\multicolumn{2}{|c|}{$\begin{array}{c}\text { Study } \\
\text { Analysis Procedure }\end{array}$}} & \multicolumn{2}{|c|}{ Empirical Formulation } & \multicolumn{3}{|c|}{ FEM } \\
\hline & & Paik $^{2}$ & Faulkner $^{3}$ & $N R-D$ & $N R-F$ & $A L-D$ \\
\hline \multirow{2}{*}{ Ultimate strength (MPa) } & uncracked unstiffened plate & 308.7 & 289 & 282.2 & 282.5 & 281.9 \\
\hline & uncracked stiffened plate & 208.2 & - & 238.1 & 240.6 & 234 \\
\hline \multirow{2}{*}{$\begin{array}{c}\text { Difference compared with } \\
\text { Paik's formula }(\%)\end{array}$} & uncracked unstiffened plate & - & -6.8 & -9.4 & -9.3 & -9.5 \\
\hline & uncracked stiffened plate & - & - & +12.6 & +13.5 & +11 \\
\hline
\end{tabular}

NR-D: Newton-Raphson (NR) procedure with Displacement (D) control

NR-F: Newton-Raphson (NR) procedure with Force (F) control

AL-D: Arc-Length (AL) procedure with Displacement (D) control

In this regard, the obtained average stress-average strain relationships along with their deflection modes superimposed on the spreads of yielding at the ultimate strength states are represented in Figs. 7-1 and 8-1.

\footnotetext{
$2 \sigma_{u}=\sigma_{Y} / \sqrt{0.995+0.17 \beta^{2}} \quad[27]$

$3 \sigma_{u}=\sigma_{Y}\left(2 / \beta-1 / \beta^{2}\right)[28]$
} 


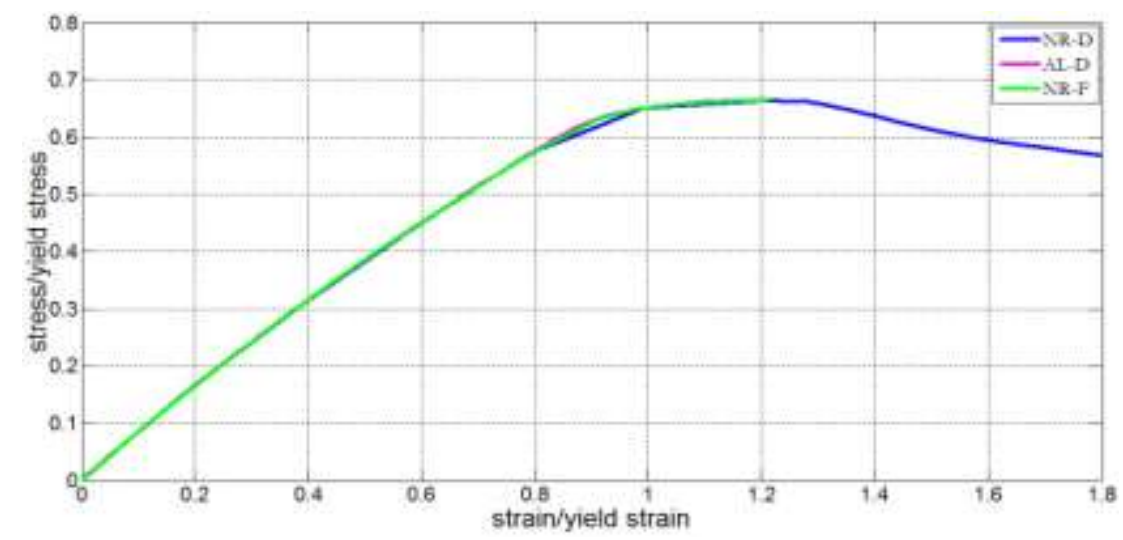

a) Nondimensional average stress-average strain curves

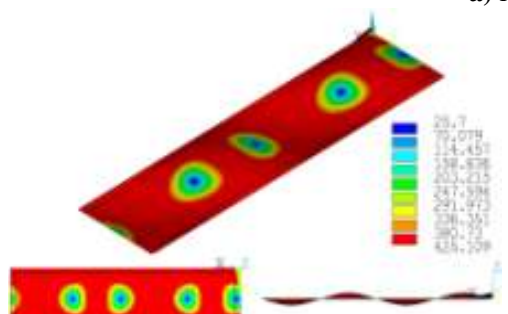

b) by NR-D
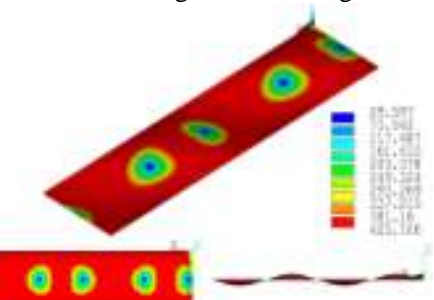

c) by NR-F

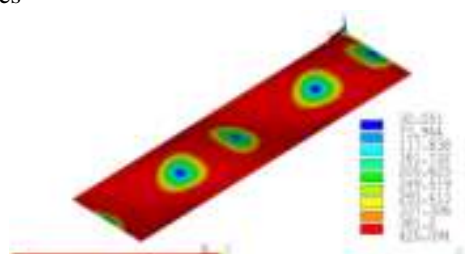

000

Fig. 7-1. uncracked plate model

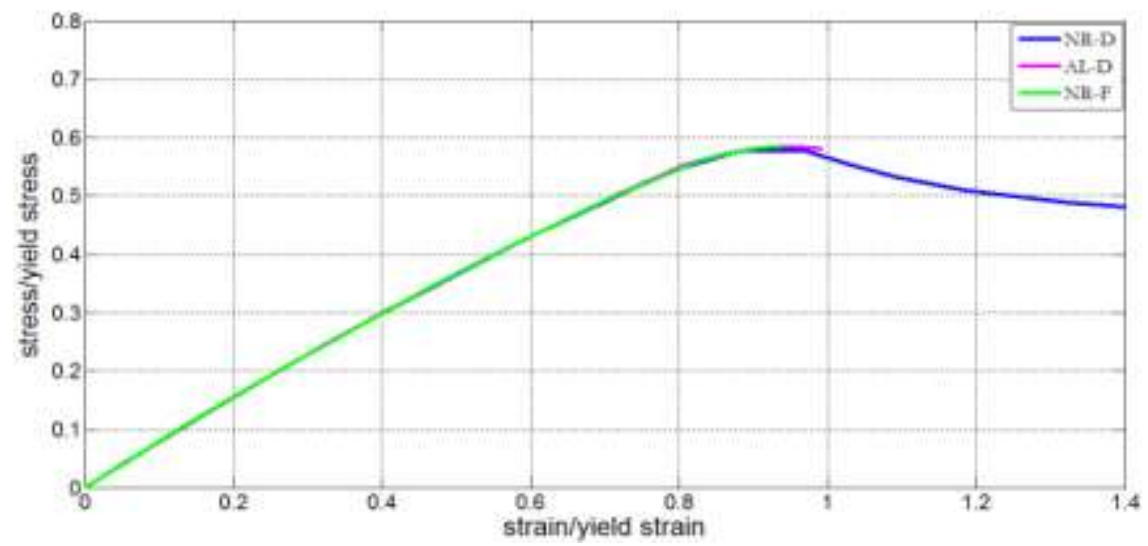

a) Nondimensional average stress-average strain curves

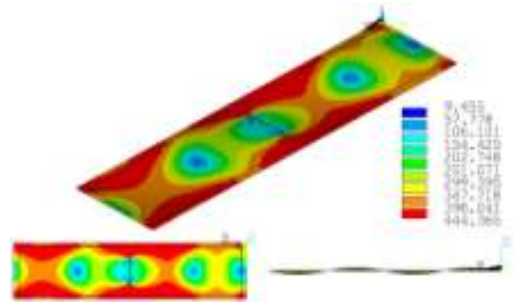

b) by NR-D

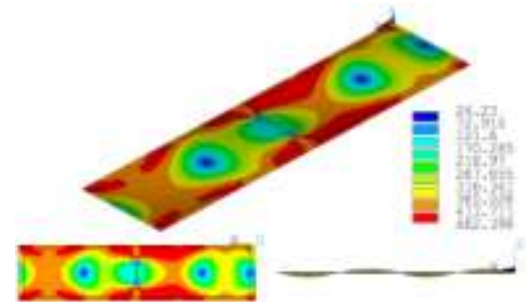

c) by NR-F

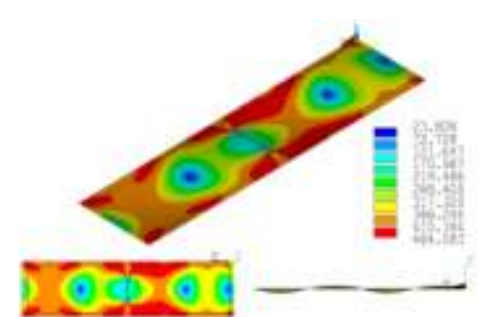

d) by AL-D

Fig. 7-2. UTC50\%

Fig. 7. Sensitivity of the ultimate strength analysis to the application of Newton-Raphson (NR) and Arc-Length (AL) procedures for the uncracked plate and UTC50\% models. (a) nondimensional average stress-average strain curves (b)-(d) deflection modes, and spreads of yielding (in $\mathrm{MPa}$ ) at ultimate strength level (with magnification of $\times 5$ )

In addition to the above, the sensitivity of the ultimate strength values for two typical cracked models (i.e. UTC50\% and STC50\%) is analysed using different solution strategies, namely Newton-Raphson and Arc-length methods. The obtained results are depicted in Figs. 7-2 and 8-2 as well as Table 4. 


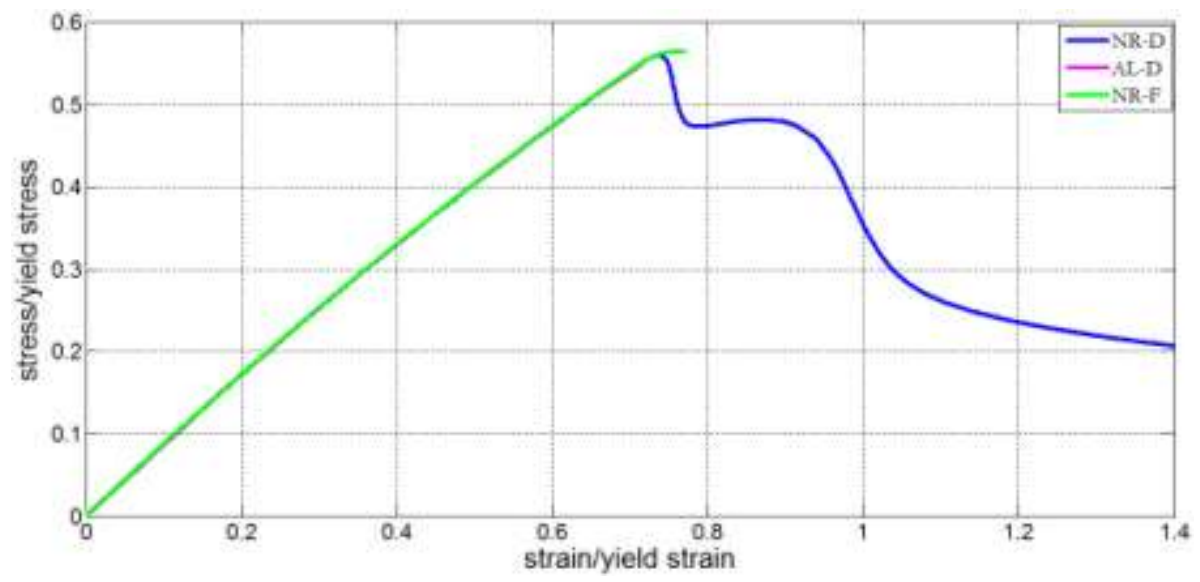

a) Nondimensional average stress-average strain curves

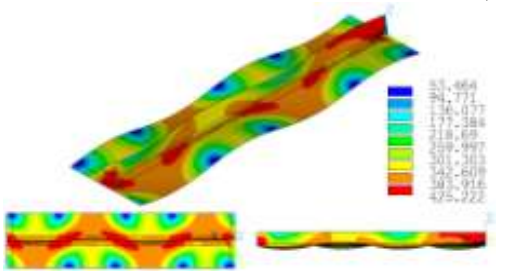

b) by NR-D

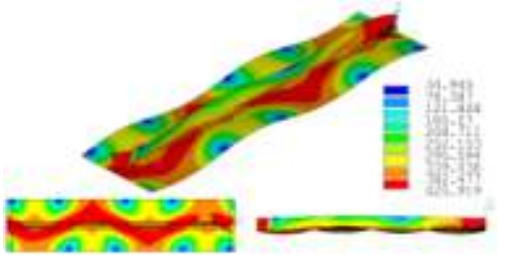

c) by NR-F

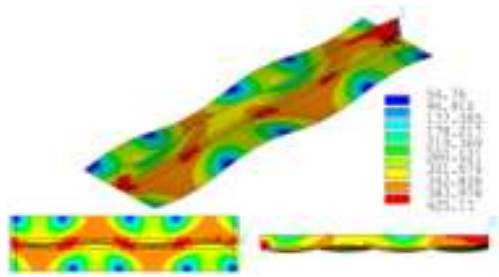

d) by AL-D

Fig. 8-1. uncracked stiffened plate model

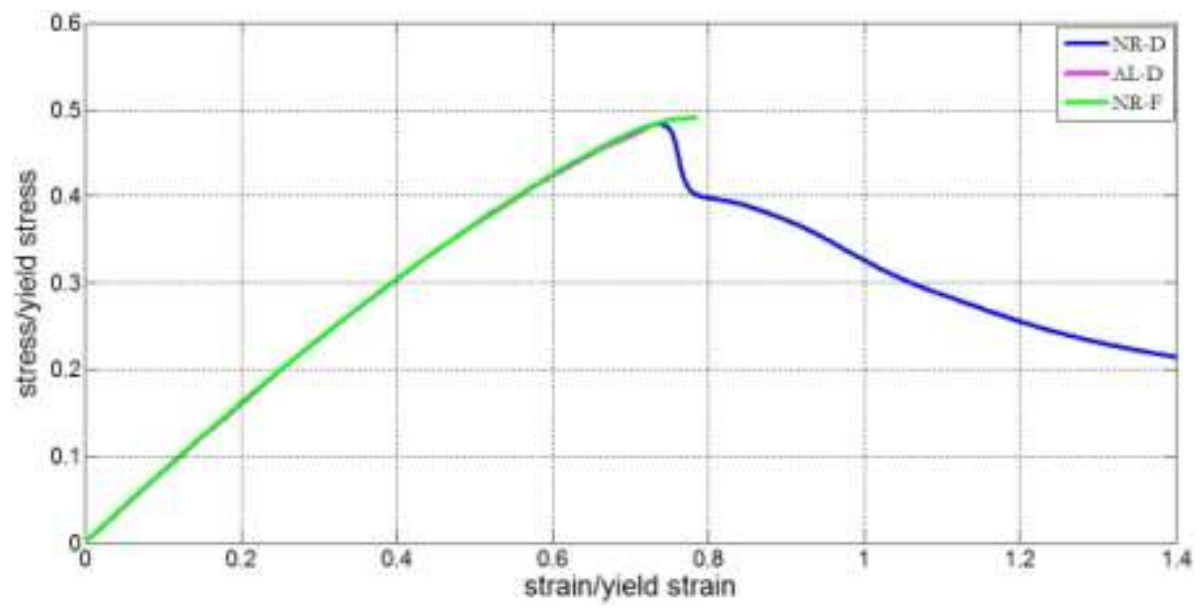

a) Nondimensional average stress-average strain curves

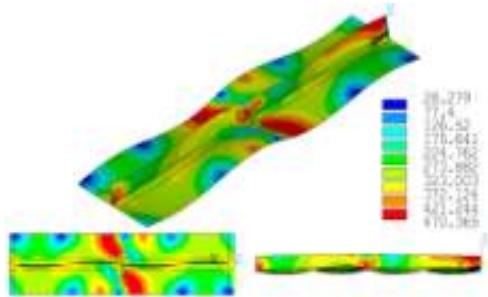

b) by NR-D

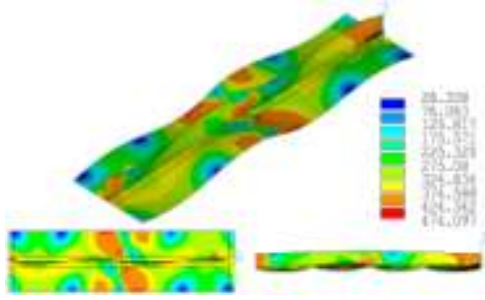

c) by NR-F

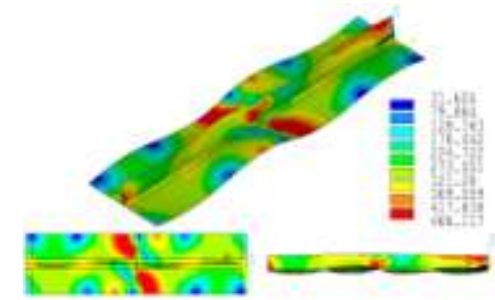

d) by AL-D

Fig. 8-2. STC50\%

Fig. 8. Sensitivity of the ultimate strength analysis to the application of Newton-Raphson (NR) and Arc-Length (AL) procedures for the uncracked stiffened plate and STC50\% models. (a) nondimensional average stress-average strain curves (b)-(d) deflection modes, and spreads of yielding (in MPa) at ultimate strength level (with magnification of $\times 5$ ) 
Table 4

Sensitivity of the ultimate strength values of UTC50\% and STC50\% models to the application of Newton-Raphson (NR) and Arc-Length (AL) procedures

\begin{tabular}{cccccccc}
\hline Model & \multicolumn{3}{c}{ UTC50\% } & \multicolumn{3}{c}{ STC50\% } \\
\cline { 7 - 8 } Analysis Procedure & NR-D & NR-F & AL-D & & NR-D & NR-F & AL-D \\
\hline Ultimate strength (MPa) & 245.2 & 248.9 & 248.2 & 205.5 & 208.5 & 202.9 \\
\hline $\begin{array}{c}\text { Difference compared with } \\
\text { NR-D method (\%) }\end{array}$ & - & +1.5 & +1.2 & - & +1.4 & -1.3 \\
\hline
\end{tabular}

NR-D: Newton-Raphson (NR) procedure with Displacement (D) control

NR-F: Newton-Raphson (NR) procedure with Force (F) control

AL-D: Arc-Length (AL) procedure with Displacement (D) control

\section{Results \&Discussions}

All of the cases described in Table 1 have been analysed through 'NR-D' procedure since it's more suitable. The nondimensional average stress-average strain relationships for all cases, in addition to their deflection modes and spreads of yielding at ultimate strength level, have been obtained and shown with details in Figs. 9 to 14. In what follows, the obtained results and the effects of some parameters on them are described and discussed with details.

\subsection{Crack length influence}

In order to examine the effect of crack length on the ultimate strength characteristics, the crack location has been kept constant while its length alters. For each of the case studies, the results are explained below.

\section{- Unstiffened plate with a transverse crack located in the centre (UTC)}

The effect of the crack length on the average stress-average strain relationship of the 'UTC' model is shown in the Fig. 9. Also deflection modes superimposed on the spreads of yielding at the ultimate strength state for different crack lengths are represented in the Fig. 9. Figure 9 reveals the fact that the increase of the crack length above $200 \mathrm{~mm}$ causes some changes in the average stress-average strain curves around the ultimate strength level. Tangent stiffness, buckling strength and ultimate strength are almost similar for the cases in which the crack length is less than $200 \mathrm{~mm}$, Fig. 9(a). 


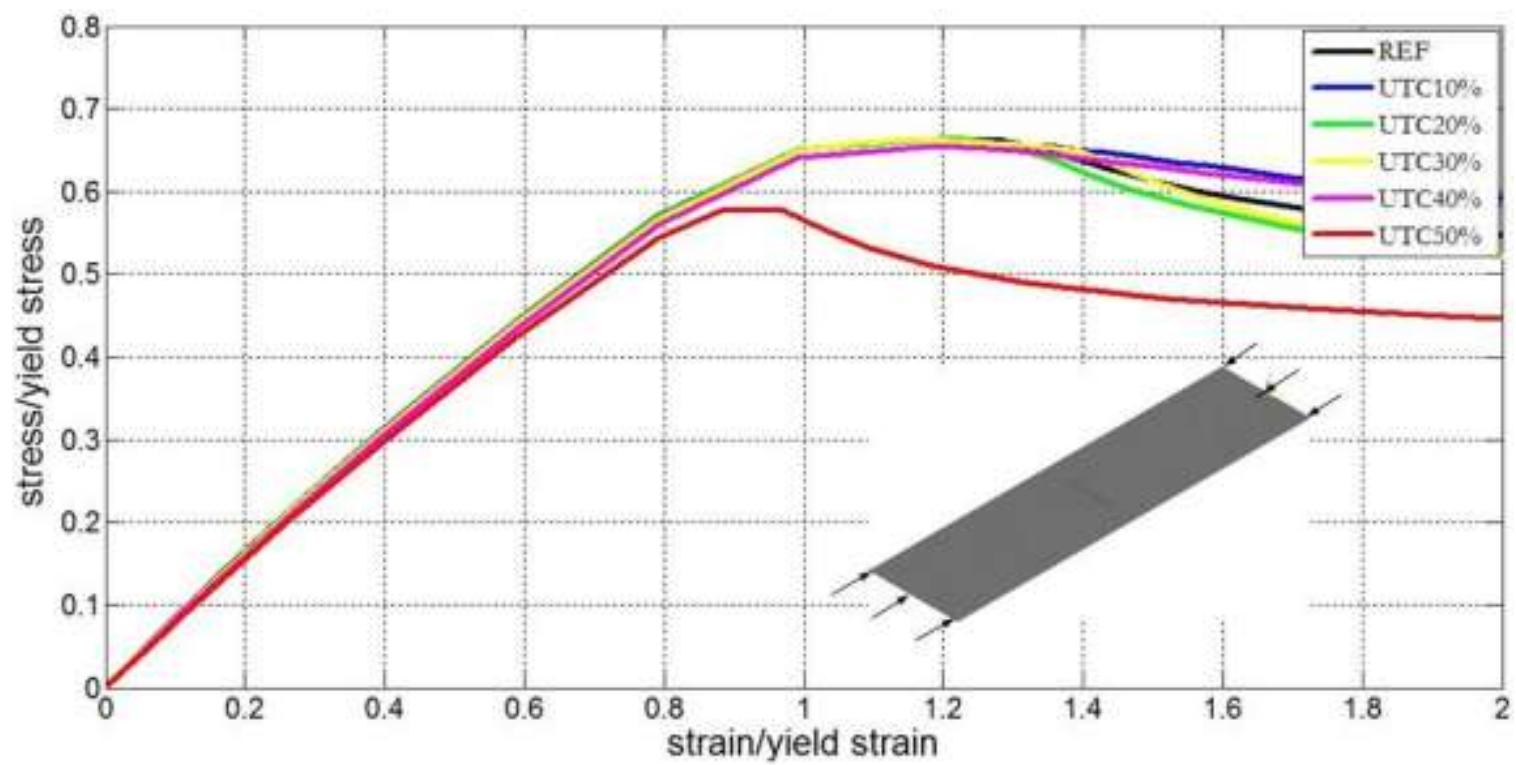

a) Nondimensional average stress-average strain curves

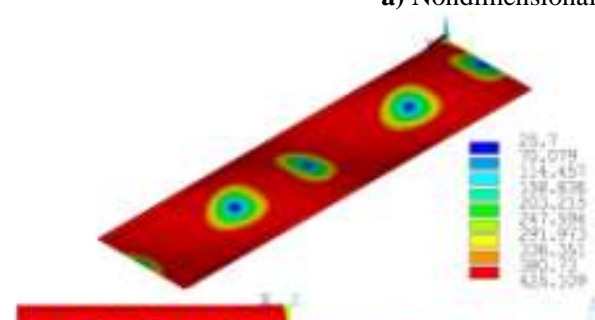

$\circ \circ 0$

b) REF
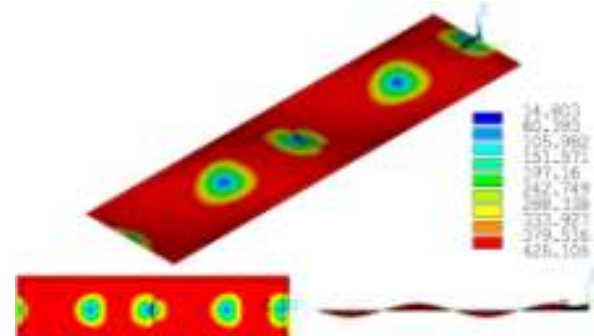

d) $\mathrm{UTC} 20 \%$

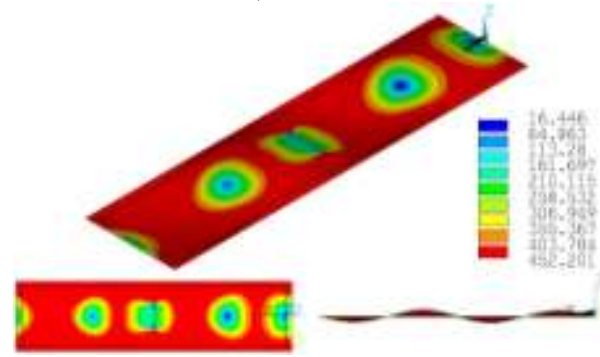

f) UTC40\%

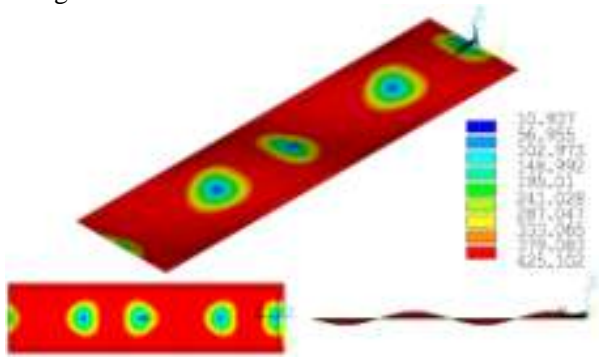

c) UTC10\%
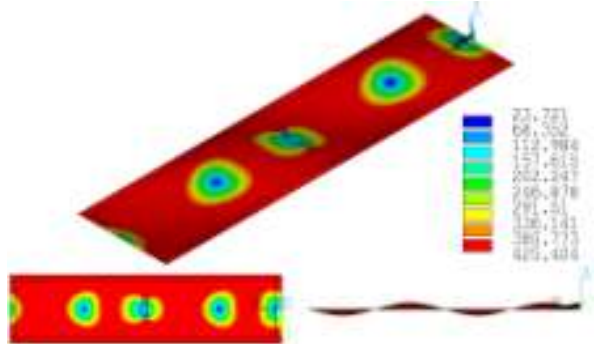

e) UTC $30 \%$

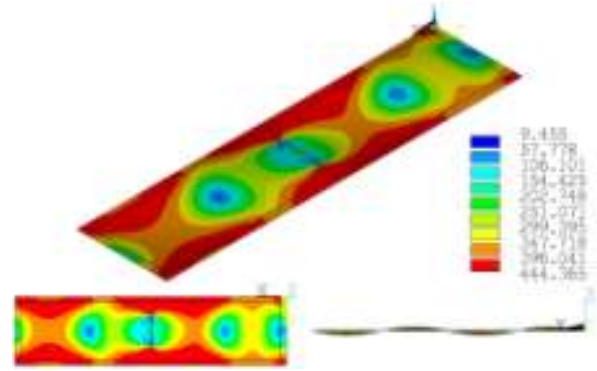

g) UTC50\%

Fig. 9. Effect of the crack length on the analysis results for the model 'UTC'. (a) nondimensional average stressaverage strain curves (b)-(g) deflection modes, and spreads of yielding (in MPa) at ultimate strength level (with magnification of $\times 5$ )

Values of the ultimate strength for the model 'UTC' having different crack lengths are given in Table 6 from which it can be understood that in comparison with the reference model, increasing the crack length above $40 \%$ of the plate breadth leads to more reduction in the ultimate strength. 


\section{- Unstiffened plate with a transversely oriented mid-length edge crack (UT1E)}

Figure 10 demonstrates the effect of the crack length on the average stress-average strain relationship of the 'UT1E' model. Also deflection modes superimposed on the spreads of yielding at the ultimate strength state for different crack lengths are represented in the Fig. 10. Figure 10 reveals the fact that the increase of the crack length affects the average stress-average strain curve almost from the beginning. Apparently tangent stiffness, buckling strength, ultimate strength and reserve strength are all decreased with the increase in the crack length, Fig. 10 (a). In addition, with the increase in the length of a crack, spread of yielding is more focused around the crack itself and also unloading takes place in the rest of the plate as can be seen in the Fig. 10 (e)-(g). 


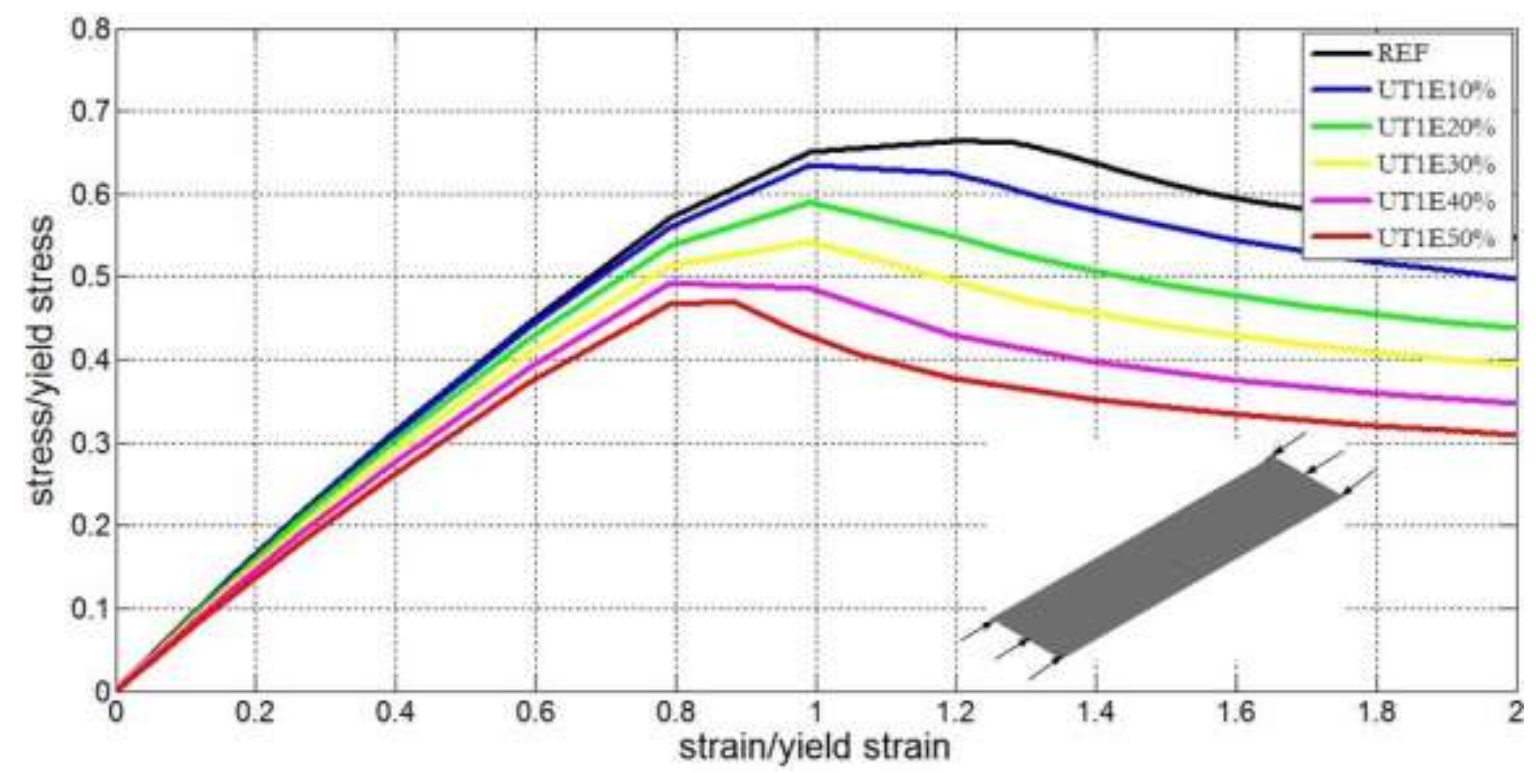

a) Nondimensional average stress-average strain curves

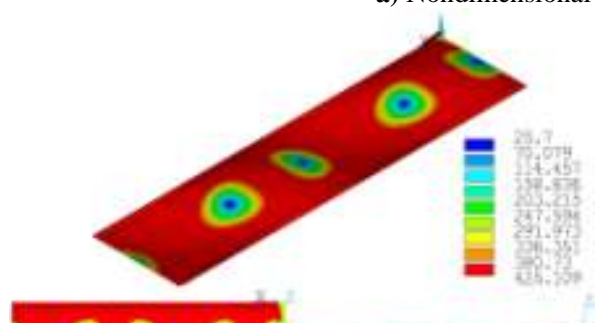

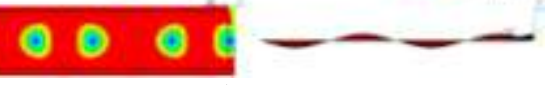

b) REF

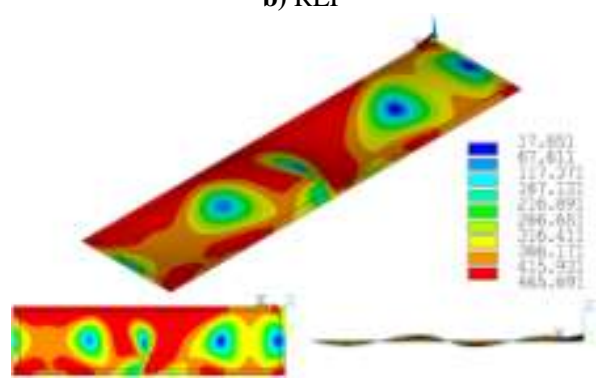

d) UT1E20\%

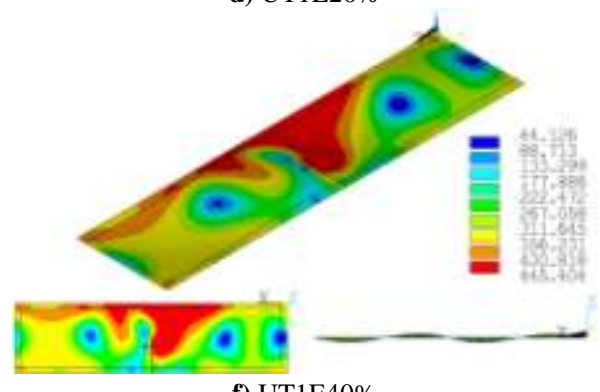

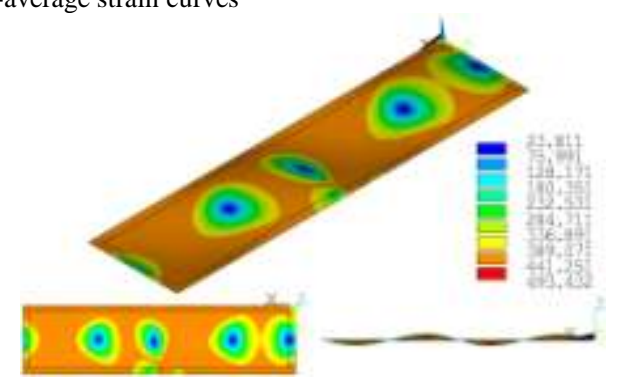

c) UT1E10\%

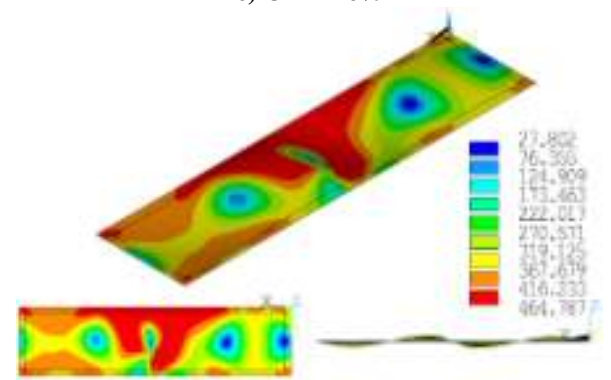

e) UT1E30\%

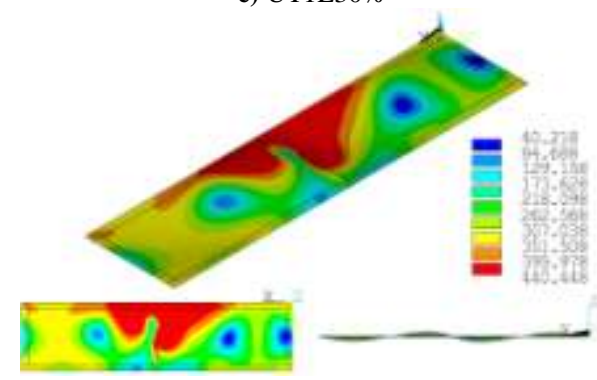

g) UT1E50\%

Fig. 10. Effect of the crack length on the analysis results for the model 'UT1E'. (a) nondimensional average stressaverage strain curves (b)-(g) deflection modes, and spreads of yielding (in MPa) at ultimate strength level (with magnification of $\times 5$ )

Values of the ultimate strength for the model 'UT1E' having different crack lengths are given in Table 6 from which it can be understood that in comparison with the reference model, increasing the crack length leads to a larger reduction of the ultimate strength. 


\section{- Unstiffened plate with two transversely oriented mid-length edge cracks (UT2E)}

Figure 11 demonstrates the effect of the crack length on the average stress-average strain relationship of the 'UT2E' model. Also deflection modes superimposed on the spreads of yielding at the ultimate strength state for different crack lengths are represented in the Fig. 11. Figure 11 reveals the fact that the increase of the crack length affects the average stress-average strain curve almost from the beginning. Apparently tangent stiffness, buckling strength, ultimate strength and reserve strength are all decreased with the increase in the crack length, Fig. 11 (a). In addition, with the increase in the length of two cracks, spread of yielding is more focused between the cracks and also unloading takes place in the rest of the plate as can be seen in the Fig. $11(\mathrm{e})-\mathrm{g})$. 

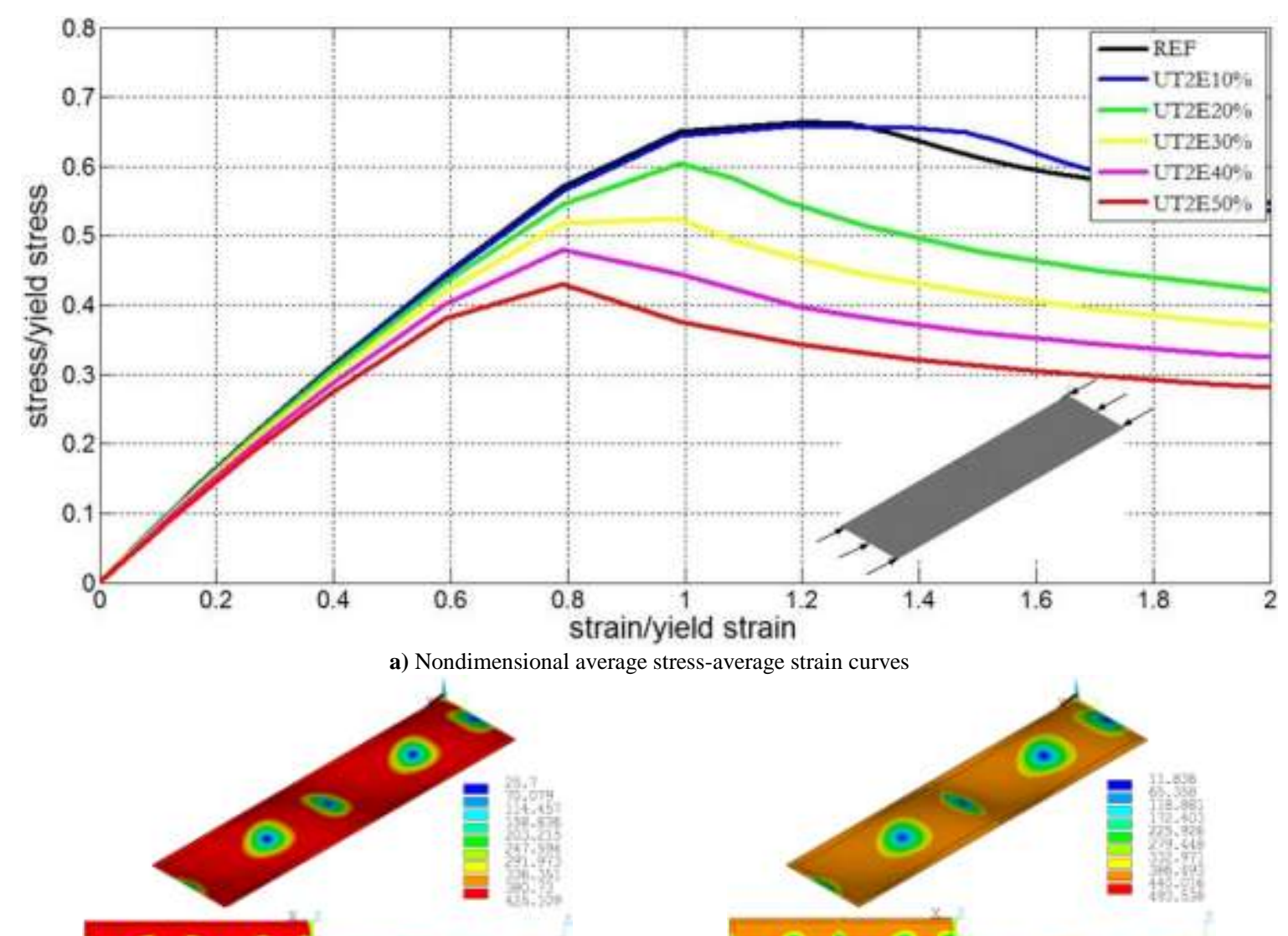

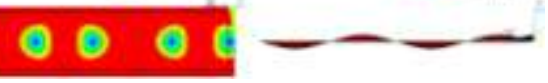

b) REF

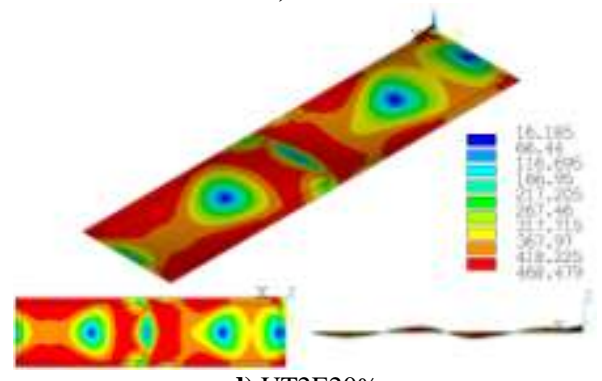

d) UT2E20\%

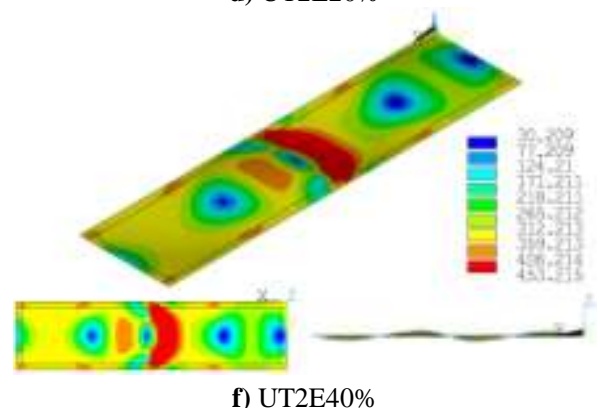

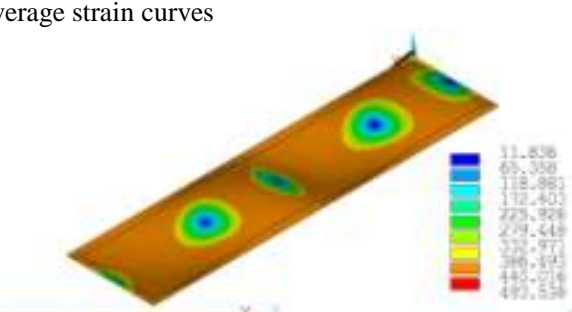

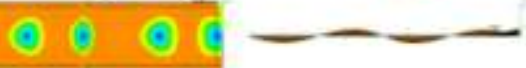

c) UT2E10\%

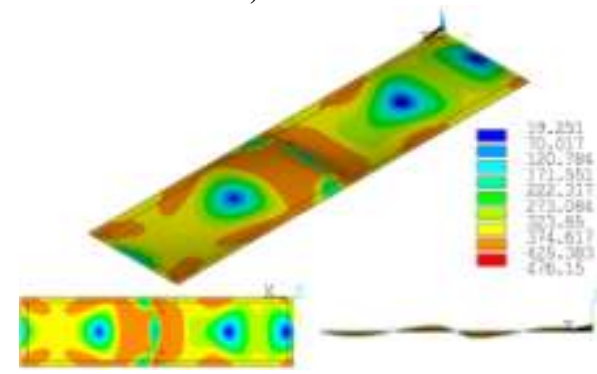

e) UT2E30\%

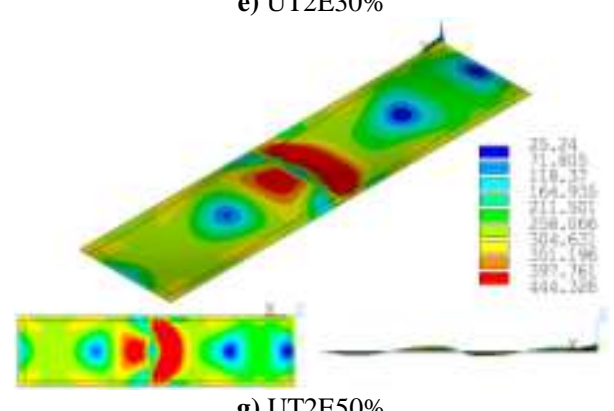

Fig. 11. Effect of the crack length on the analysis results for the model 'UT2E'. (a) nondimensional average stressaverage strain curves (b)-(g) deflection modes, and spreads of yielding (in MPa) at ultimate strength level (with magnification of $\times 5$ )

Values of the ultimate strength for the model 'UT2E' having different crack lengths are given in Table 6 from which it can be understood that in comparison with the reference model, increasing the crack length above $10 \%$ of the plate breadth leads to a larger reduction of the ultimate strength. 
- Stiffened plate with a transverse crack located in the centre of the plate (STC)

Figure 12 shows the effect of the crack length on the average stress-average strain relationship of the 'STC' model. The deflection modes and spreads of yielding at the ultimate strength state for different crack lengths are represented in the Fig. 12. It can be concluded that with the increase of the crack length, the average stressaverage strain curves are changed for a stress level above $\sigma / \sigma_{Y}=0.15$. The longer the crack, the more reduced the stiffness and ultimate strength of the model. In addition, with the increase in the length of the central crack, local plastic deformations are concentrated in the middle region of the model; whilst the rest of the model undergoes unloading, as can be seen in the Fig. 12 (e)-(g). 


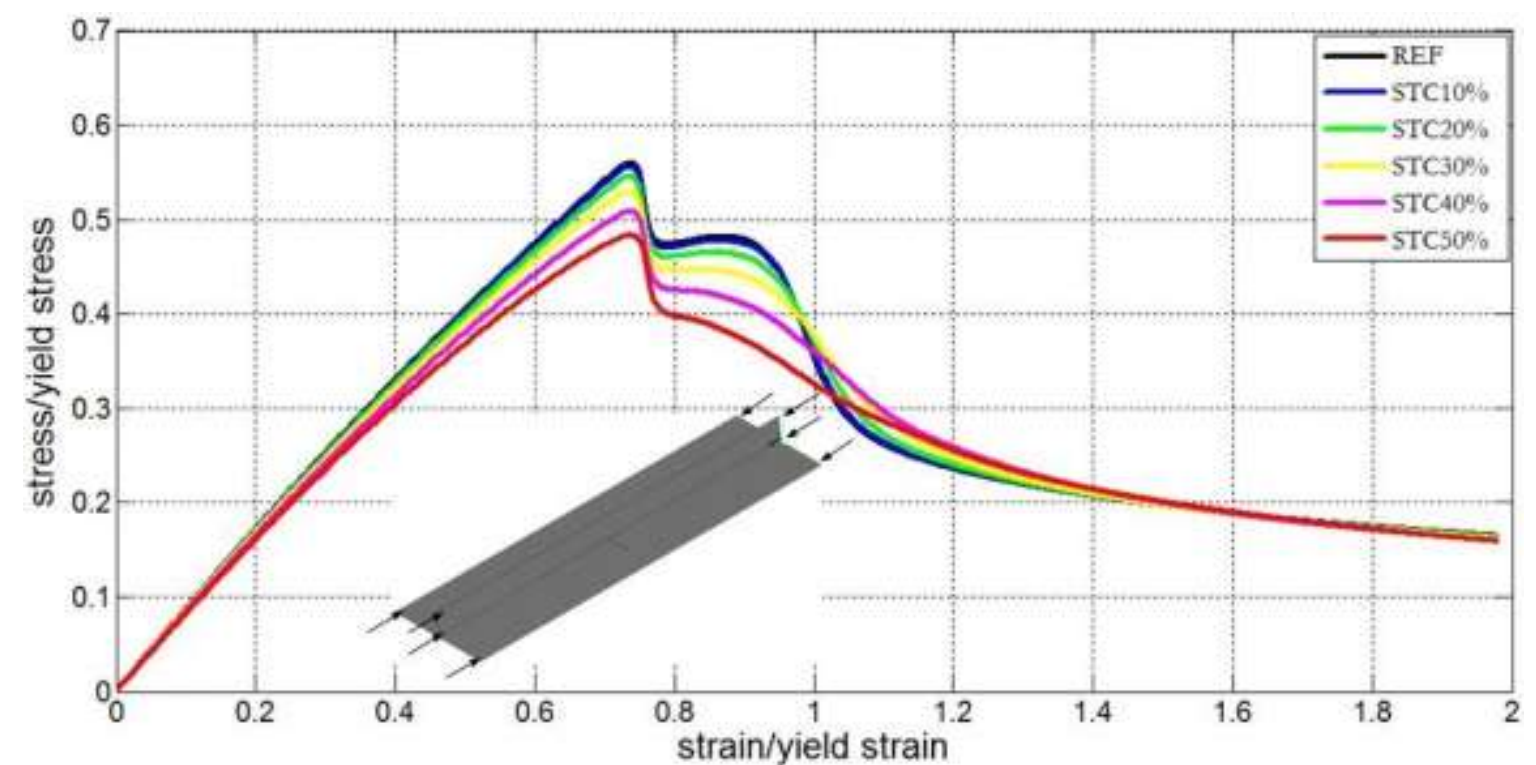

a) Nondimensional average stress-average strain curves

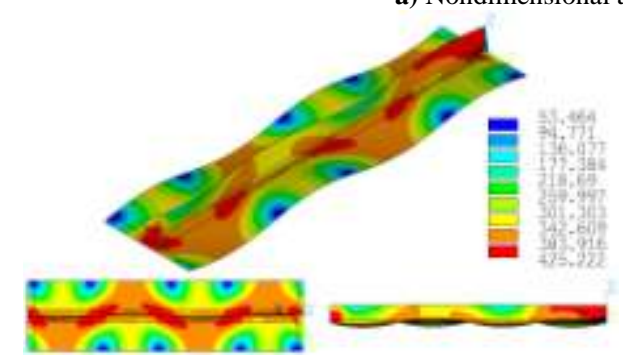

b) REF

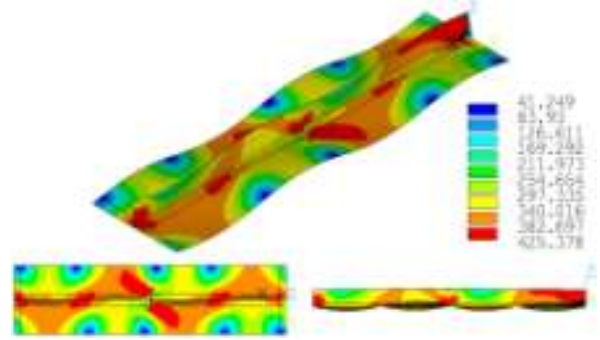

d) $\mathrm{STC} 20 \%$

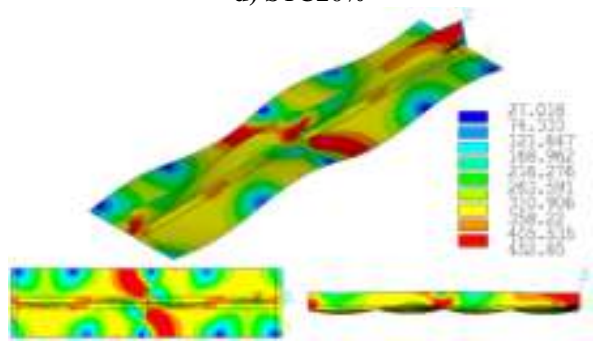

f) $\mathrm{STC} 40 \%$

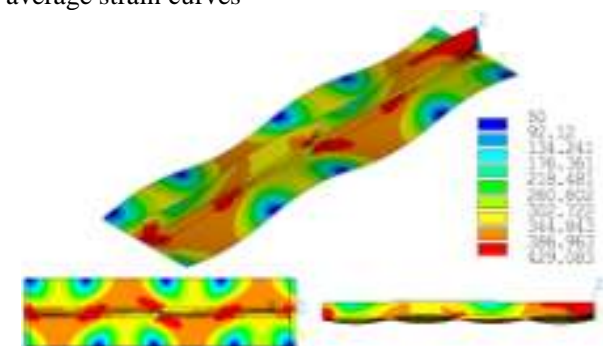

c) $\mathrm{STC} 10 \%$

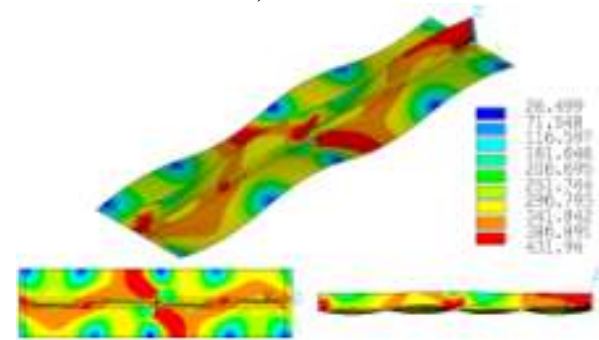

e) $\mathrm{STC} 30 \%$

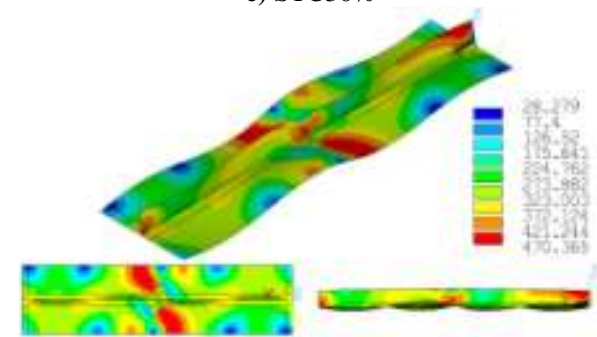

g) $\mathrm{STC} 50 \%$

Fig. 12. Effect of the crack length on the analysis results for the model 'STC'. (a) nondimensional average stressaverage strain curves (b)-(g) deflection modes, and spreads of yielding (in $\mathrm{MPa}$ ) at ultimate strength level (with magnification of $\times 5$ )

Values of the ultimate strength for the model 'STC' having different crack lengths are given in Table 5 from which it can be understood that in comparison with the reference model, increasing the crack length above $20 \%$ of the plate breadth leads to a larger reduction in the ultimate strength. 
Table 5

Values of the ultimate strength for the models 'STC' and 'STCW' having different crack lengths in comparison with the ultimate strength of the model 'REF'

\begin{tabular}{|c|c|c|c|c|c|c|c|c|c|c|c|}
\hline \multirow{2}{*}{ Model } & \multirow{2}{*}{$R E F$} & \multicolumn{5}{|c|}{ STC } & \multicolumn{5}{|c|}{ STCW } \\
\hline & & $10 \%$ & $20 \%$ & $30 \%$ & $40 \%$ & $50 \%$ & $10 \%$ & $20 \%$ & $30 \%$ & $40 \%$ & $\mathbf{5 0 \%}$ \\
\hline Ultimate strength (MPa) & 238.1 & 236.4 & 231.9 & 225 & 216.2 & 205.5 & 230.9 & 230.1 & 229.9 & 230.4 & 231.7 \\
\hline Difference (\%) & - & -0.7 & -2.7 & -5.8 & -10.1 & -15.9 & -3.1 & -3.5 & -3.6 & -3.3 & -2.8 \\
\hline
\end{tabular}

\section{- Stiffened plate with two cracks located in the plate and the stiffener web (STCW)}

'STCW' model is a stiffened plate model suffering a transverse crack (with constant length $20 \%$ of the plate breadth) in the centre of the plate and also an additional crack in the stiffener web initiating from the middle of the longitudinal edge of web-plate junction (with a length from 10\%-50\% of the web height). Figure 13 shows the effect of the stiffener crack length on the average stress-average strain relationship of this model. The deflection modes and spreads of yielding at the ultimate strength state for this model considering different crack lengths are represented in the Fig. 13. It can be concluded that with the increase of the length of the crack in the stiffener web, the average stress-average strain curves are slightly changed for a stress level above $\sigma / \sigma_{Y}=0.3$. The longer the crack, the more reduced the stiffness and ultimate strength of the model. 


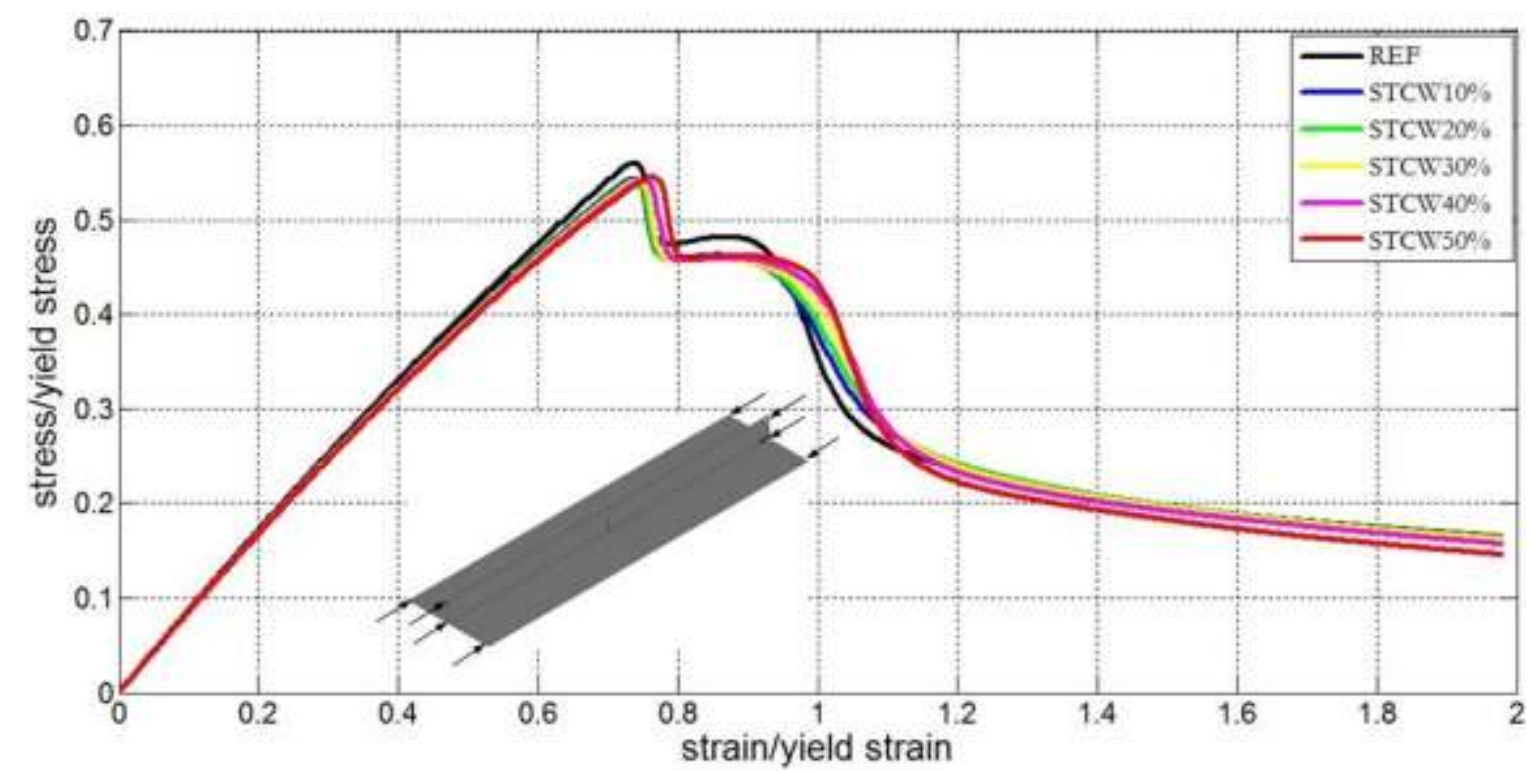

a) Nondimensional average stress-average strain curves

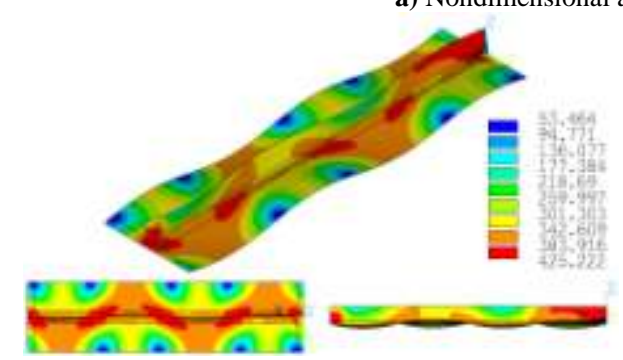

b) REF

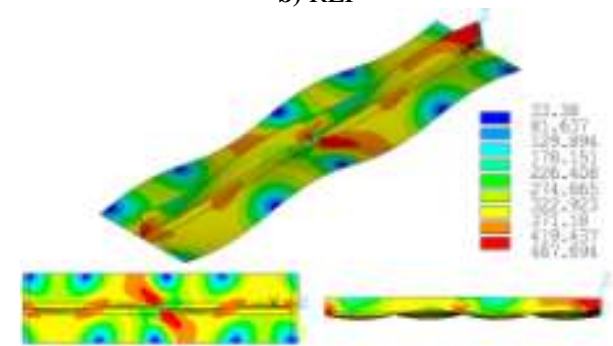

d) $\mathrm{STCW} 20 \%$

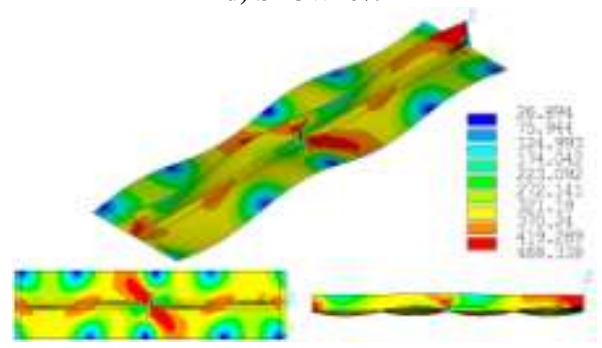

f) $\mathrm{STCW} 40 \%$

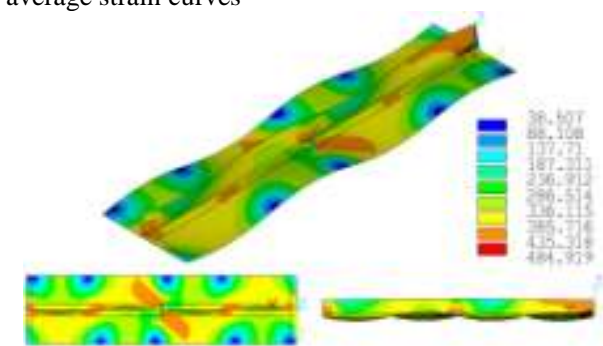

c) $\mathrm{STCW} 10 \%$

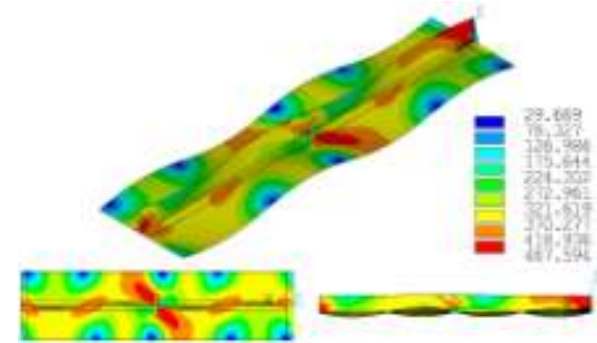

e) $\mathrm{STCW} 30 \%$

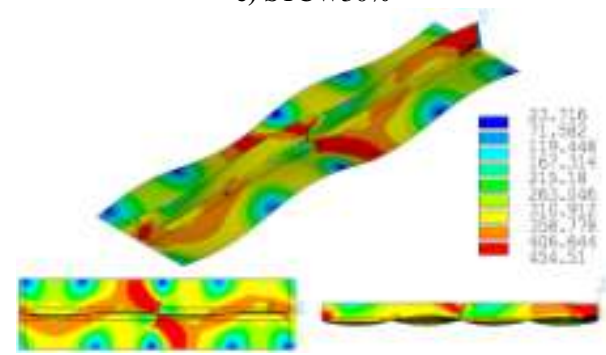

g) STCW50\%

Fig. 13. Effect of the crack length on the analysis results for the model 'STCW'. (a) nondimensional average stressaverage strain curves (b)-(g) deflection modes, and spreads of yielding (in $\mathrm{MPa}$ ) at ultimate strength level (with magnification of $\times 5$ )

Values of the ultimate strength for the model 'STCW' having different crack lengths are given in Table 5 from which it can be understood that in comparison with the reference model, increasing the crack length does not lead to a considerable reduction in the ultimate strength. 


\subsection{Crack location influence}

In order to more clearly examine the effect of crack location on the ultimate strength characteristics in case of unstiffened plate models, the obtained results are given in Table 6. In fact, for each crack length kept constant (e.g. 10\%), the location of crack is changed (i.e. UTC, UT1E and UT2E). As it can be seen, there are considerable differences between the obtained values of the ultimate strength for the analysed cases of the models 'UTC' and, 'UT2E' and 'UT1E', when the crack gets longer than $10 \%$ of the plate breadth (i.e. $50 \mathrm{~mm}$ ). In other words, moving the crack with a length of more than $10 \%$ of the plate breadth, affects the ultimate strength magnitude. In this regard, it can also be realised from Figs. 9 to 11 that the spreads of yielding are different although the deflection modes are similar at the ultimate strength state.

\section{Table 6}

Influence of crack location on the values of the ultimate strength in case of unstiffened plates

\begin{tabular}{|c|c|c|c|}
\hline & Case & Ultimate strength $(\mathrm{MPa})$ & Difference (\%) \\
\hline & REF & 282.2 & - \\
\hline \multirow{3}{*}{$10 \%$} & UTC & 282.2 & 0 \\
\hline & UT1E & 270 & -4.5 \\
\hline & UT2E & 280.1 & -0.7 \\
\hline \multirow{3}{*}{$20 \%$} & UTC & 282.2 & 0 \\
\hline & UT1E & 251.1 & -12.4 \\
\hline & UT2E & 256.8 & -9.9 \\
\hline \multirow{3}{*}{$30 \%$} & UTC & 281.8 & -0.1 \\
\hline & UT1E & 230.5 & -22.4 \\
\hline & UT2E & 223 & -26.5 \\
\hline \multirow{7}{*}{$40 \%$} & UTC & 278.2 & -1.4 \\
\hline & UT1E-L250 & 198.3 & -42.3 \\
\hline & UT1E-L500 (UT1E) & 209.1 & -35 \\
\hline & UT1E-L750 & 198 & -42.5 \\
\hline & UT1E-L1000 & 209.1 & -35 \\
\hline & UT1E-L1250 & 197.9 & -42.6 \\
\hline & UT2E & 203.9 & -38.4 \\
\hline \multirow{3}{*}{$50 \%$} & UTC & 245.2 & -15.1 \\
\hline & UT1E & 200 & -41.1 \\
\hline & UT2E & 182.6 & -54.5 \\
\hline
\end{tabular}

Meanwhile, the effects of moving the crack with a fixed length $40 \%$ of the plate breadth (i.e. $200 \mathrm{~mm}$ ) along the unloaded edge of a plate model have been also examined and the results are given in Fig. 14 and Table 6. The ultimate strength of the plate having such an edge crack is much more reduced in cases where the crack locates at the longitudinal coordinates of $250 \mathrm{~mm}, 750 \mathrm{~mm}$ and $1250 \mathrm{~mm}$, in comparison with the other cases where the crack lies at a distance of $500 \mathrm{~mm}$ or $1000 \mathrm{~mm}$ from the loaded edge of the plate (Table 6). This is 
because in the cases where the crack locates at the longitudinal coordinates of $250 \mathrm{~mm}, 750 \mathrm{~mm}$ and $1250 \mathrm{~mm}$, the crack causes a critical separation in the longitudinal edge strips of the plate that are resisting against the inplane compression. This is while for the other cases having a crack at a longitudinal coordinate of $500 \mathrm{~mm}$ or $1000 \mathrm{~mm}$, the crack separates these resisting edge strips in a very lower sensitive place, right at the transverse boundaries between the half-waves.

Moving the edge crack along the longitudinal edge of the plate causes also movement of the highly stressed region of the plate that is in conjunction with the crack itself. The collapse modes in the cases where the crack locates at the longitudinal coordinates of $250 \mathrm{~mm}, 750 \mathrm{~mm}$ and $1250 \mathrm{~mm}$ include three regular buckling halfwaves and one roof-mode half wave. In the cases where the crack is at the longitudinal coordinates of $500 \mathrm{~mm}$ and $1000 \mathrm{~mm}$, the deflection modes at the ultimate strength level take the form of regular buckling half-waves. 

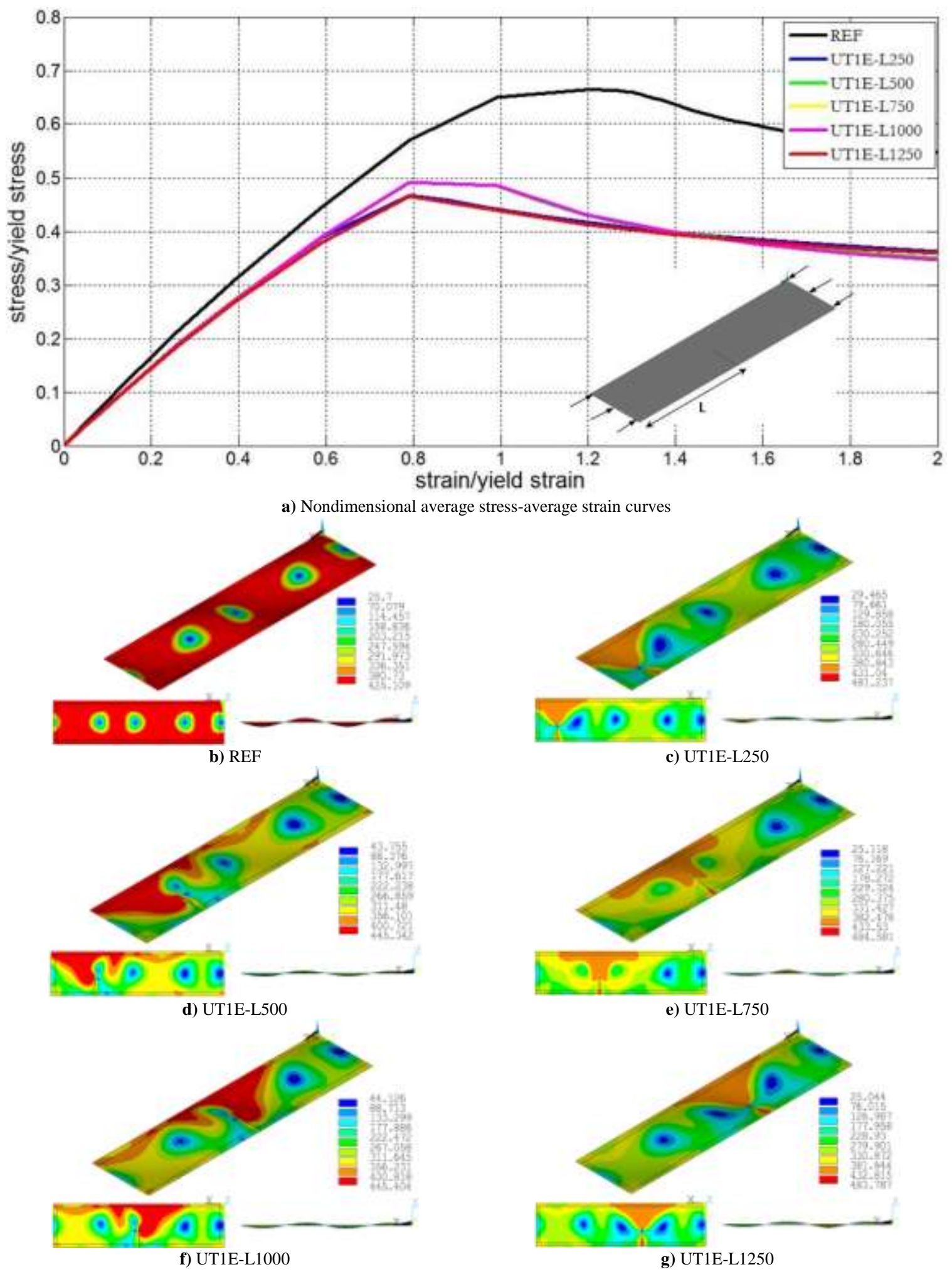

Fig. 14. Effect of the crack location on the analysis results for the model 'UT1E-L'. (a) nondimensional average stressaverage strain curves (b)-(g) deflection modes, and spreads of yielding (in MPa) at ultimate strength level (with magnification of $\times 5$ ) 


\section{Conclusions}

The main objective of this paper is to numerically investigate the influence of crack on ultimate strength characteristics of imperfect unstiffened and stiffened plate elements used in a thin-walled structure such as a ship. In this regard, different cracking defects (in terms of crack length and location) have been taken into account in respective structural components based on the reduced cross-sectional area, having no contact between their faces and no propagation was allowed. The models included initial distortions due to the fabrication process. The nonlinear responses of the different study cases have been obtained employing NewtonRaphson method. Both material and geometric nonlinearities have been considered in the analyses. After performing a series of nonlinear finite element calculations using ANSYS commercial finite element code, the influences of crack length and especially crack location upon the magnitude of ultimate strength have been investigated.

It was revealed that the most critical type of the cracks is those ones that are transversally located along the longitudinal (unloaded) edges of the plate. In this regard, the observations indicate that the reduction in ultimate strength in case of two transversely oriented mid-length edge cracks is less than that for single edge crack as long as the total length of crack gets shorter than $30 \%$ of the plate breadth.

Also in the case of a transversely oriented edge crack in which the crack moves along the unloaded edge, the ultimate strength is more reduced for crack located at the crest or the trough of plating half-wave than for cases with crack located at zero amplitude of plating half-wave.

Such findings can be taken into consideration from a structural strength assessment point of view throughout the fabrication process and also for the duration of repair and maintenance.

Influence of cracks parallel to longitudinal welding lines or the effect of oriented cracks in general on the ultimate strength characteristics can be investigated as future works. Further investigations into the behaviour of plate and stiffened plate elements incorporating propagating cracks in any direction can also be performed as future studies. 


\section{References}

[1] Özgüç Ö et al. The new simple design equations for the ultimate compressive strength of imperfect stiffened plates. Ocean Engineering 2007; 34: 970-986.

[2] Masaoka K and Mansour A. Compressive strength of stiffened plates with imperfections: Simple design equations. Journal of Ship Research 2008; 52 (No. 3): 227-337.

[3] Paik JK and Sohn JM. Effects of welding residual stresses on high tensile steel plate ultimate strength: Nonlinear finite element method investigations. In: Proceedings of the $28^{\text {th }}$ International Conference on Offshore Mechanics and Arctic Engineering (OMAE), Honolulu, Hawaii, 2009.

[4] Chaithanya PP et al. The effect of distortion on the buckling strength of stiffened panels. Ships and Offshore Structures 2010; 5 (No. 2): 141-153.

[5] Wang F and Cui W. On the engineering approach to estimating the parameters in an improved crack growth rate model for fatigue life prediction. Ships and Offshore Structures 2010; 5 (No. 3): 227-241.

[6] Wang F et al. Applicability of the improved crack growth rate model and its parameters estimation method. Journal of Ship Mechanics 2010; 14 (No. 3): 252-262.

[7] Xiao-dong $\mathrm{X}$ et al. A comparison between two models of fatigue crack growth under overload. Journal of Ship Mechanics 2010; 14 (No. 3): 263-271.

[8] Brighenti R. Numerical buckling analysis of compressed or tensioned cracked thin plates. Engineering Structures 2005; 27: 265-276.

[9] Brighenti R. Buckling of cracked thin-plates under tension or compression. Thin-Walled Structures 2005; 43: 209-224.

[10] Alinia MM et al. Influence of central cracks on buckling and post-buckling behaviour of shear panels. Thin-Walled Structures 2007; 45: 422-431.

[11] Alinia MM et al. Numerical modelling for buckling analysis of cracked shear panels. Thin-Walled Structures 2007; 45: 1058-1067.

[12] Brighenti R. Buckling sensitivity analysis of cracked thin plates under membrane tension or compression loading. Nuclear Engineering and Design 2009; 239: 965-980.

[13] Khedmati MR et al. Sensitivity analysis of the elastic buckling of cracked plate elements under axial compression. Thin-Walled Structures 2009; 47: 522-536.

[14] Brighenti R, Carpinteri A. Buckling and fracture behaviour of cracked thin plates under shear loading. 
Materials and Design 2011; 32: 1347-1355.

[15] Seifi R, Khoda-yari N. Experimental and numerical studies on buckling of cracked thin-plates under full and partial compression edge loading. Thin-Walled Structures 2011; 49:1504-1516.

[16] Paik JK et al. Ultimate strength of cracked plate elements under axial compression or tension. Thinwalled Structures 2005; 43: 237-272.

[17] Paik JK. Residual ultimate strength of steel plates with longitudinal cracks under axial compression: Experiments. Ocean Engineering 2008; 35: 1775-1783.

[18] Paik JK. Residual ultimate strength of steel plates with longitudinal cracks under axial compression: Nonlinear finite method investigations. Ocean Engineering 2009; 36: 266-276.

[19] Margaritis Y, Toulios M. The ultimate and collapse response of cracked stiffened plates subjected to uniaxial compression. Thin-Walled Structures 2012; 50: 157-173.

[20] Ship Structure Committee report. Strength and stability testing of stiffened plate panels. SSC-339, USA, 1997.

[21] ANSYS User's Manual (Version 12.1). Houston, Swanson Analysis Systems Inc. 2009.

[22] Paik JK et al. Effect of initial deflection shape on the ultimate strength behaviour of welded steel plates under biaxial compressive loads. Journal of Ship Research 2004; 48 (No. 1): 45-60.

[23] 14th International Ship and Offshore Structures Congress report. Ultimate hull girder strength. Vol. 1, Japan, 2000.

[24] Fujikubo $\mathrm{M}$ et al. Estimation of ultimate strength of continuous stiffened panel under combined transverse thrust and lateral pressure: Part 2 (Continuous stiffened panel). Marine Structures 2005; 18: 411-427.

[25] Cook RD et al. Concepts and applications of finite element analysis. 4th ed. John Wiley \& Sons, Inc; 2002.

[26] Paik JK et al. Ultimate limit state design of steel plated structures. 1st ed. John Wiley \& Sons, Inc; 2003.

[27] Paik, J. K., T, A. K., Ultimate Limit State Design of Steel-Plated Structures, Wiley-Blackwell, 2003.

[28] D. Faulkner, Chapters 21 and 22 of Ship Structural Design Concepts, J. H. Evans, Ed., Cornell Maritime Press, 1975. 